\title{
Psychosurgery: Review of Latest Concepts and Applications
}

\author{
Sabri Aydin ${ }^{1}$ Bashar Abuzayed ${ }^{1}$ \\ ${ }^{1}$ Department of Neurosurgery, Cerrahpasa Medical Faculty, Istanbul \\ University, Istanbul, Turkey \\ J Neurol Surg A 2013;74:29-46. \\ Address for correspondence and reprint requests Bashar Abuzayed, \\ M.D., Department of Neurosurgery, Cerrahpasa Medical Faculty, \\ Istanbul University, K.M.P. Fatih, Istanbul 34089, Turkey \\ (e-mail: sylvius@live.com).
}

\begin{abstract}
Keywords

- deep brain stimulation

- neural networks

- neuromodulation

- psychiatric disorders

- psychosurgery

Although the utilization of psychosurgery has commenced in early 19th century, when compared with other neurosurgical fields, it faced many obstacles resulting in the delay of advancement of this type of surgical methodology. This was due to the insufficient knowledge of both neural networks of the brain and the pathophysiology of psychiatric diseases. The aggressive surgical treatment modalities with high mortality and morbidity rates, the controversial ethical concerns, and the introduction of antipsychotic drugs were also among those obstacles. With the recent advancements in the field of neuroscience more accurate knowledge was gained in this field offering new ideas for the management of these diseases. Also, the recent technological developments aided the surgeons to define more sophisticated and minimally invasive techniques during the surgical procedures. Maybe the most important factor in the rerising of psychosurgery is the assemblage of the experts, clinicians, and researchers in various fields of neurosciences implementing a multidisciplinary approach. In this article, the authors aim to review the latest concepts of the pathophysiology and the recent advancements of the surgical treatment of psychiatric diseases from a neurosurgical point of view.
\end{abstract}

\section{Introduction}

Psychosurgery existed long before the advent of the frontal lobotomy. There is an archeological evidence of human skull trephinations as long as 5000 years ago in Europe and Northern Africa which were performed on the basis of the psychological and spiritual understandings of that time. ${ }^{22}$ Gottlieb Burckhardt (1836 to 1907), a Swiss psychiatrist, was the first physician to perform modern psychosurgery, in which the contemporary theories about brain-behavior and brain-language relationships were interconnected and practically applied to patient care. ${ }^{77}$ However, the landmark text was dedicated to the Portuguese neurologist Egas Moniz (1874 to 1955$)^{77}$ who proposed that the prefrontal region of the brain was the "psychic center" of a person. Moniz instructed his surgical partner, Almeida Lima, to develop the "leukotome," a device that functioned as a neurosurgical apple corer, and they performed the first prefrontal leukot- omy in $1935 .^{8,22}$ Moniz's initial trial resulted in no deaths or serious morbidities, which were seen in the other treatments available for psychological disorders, such as insulin coma or electric shock therapy. The leukotomy appeared as a viable alternative and tens of thousands of these procedures were performed, however, without adequate research demonstrating the safety of the procedure or a substantial benefit for the patient. Freeman and Watts developed a modification, the "transorbital leukotomy" and performed it in $\sim 600$ patients. ${ }^{27}$ Outcomes were generally favorable, although the procedure was associated with significant morbidity. Further modifications of the leukotomy resulted in "open" techniques and included bilateral inferior leukotomy, bimedial frontal leukotomy, orbital gyrus undercutting, cerebral topectomies, and anterior cingulotomies. ${ }^{19}$ It was revealed that these procedures were not being used as ultima ratio in otherwise untreatable patients with reported cases in which little investigation was done before the received

April 13, 2011

accepted after revision

October 10, 2011

published online

October 26, 2012 (c) 2013 Georg Thieme Verlag KG Stuttgart · New York
DOI http://dx.doi.org/ 10.1055/s-0032-1304805. ISSN 2193-6315. 
operations. Neurosurgeons began to think of the procedures as imprecise and potentially dangerous and psychiatrists thought of them as ineffective and unnecessarily invasive.

With the introduction of the psychoactive drugs in 1954 and the development of further drugs, it soon became clear that these pharmaceutical therapies were safer and often more effective than the surgical procedures. ${ }^{22}$ However, psychosurgical procedures continued to be performed in the United States and other countries and some clinicians believed that it was underused. ${ }^{22}$ The development of stereotactic neurosurgery, which allowed more precise anatomical targeting, led to safer and more effective means of operating on brain diseases. Also, there was an expanded understanding of the neural circuitry involved in the pathogenesis of neurologic and psychiatric disorders. Success in the field of movement disorders with ablation of deep brain targets encouraged the development of similar ablative procedures for treating mental illness. These operations included the limbic leukotomy, subcaudate tractotomy, anterior internal capsulotomy, and cingulotomy. ${ }^{21}$

Now, with the marked development of modern imaging and concept driven psychiatric interventions, newer surgical therapies focusing on neural modulation were introduced, including the electrical stimulation of the vagus nerve (VNS) and deep brain stimulation (DBS). ${ }^{6}$ These methods were found more acceptable from the ethical standpoint because they are relatively noninvasive and reversible. ${ }^{56}$ With ongoing laboratory and clinical researches introducing new therapeutic targets, the spectrum of psychiatric disorders that are treated with DBS continues to grow.

\section{Overview of the Neuroanatomy of Behavior}

\section{Emotional Brain}

The emotional brain consists of the regions involved in the Papez circuit (the hippocampus, the fornix, the mammillary bodies, the mammillothalamic tract, the anterior thalamic, the subgenual cingulate (SCG) [Brodman area 25 or Cg25], the parahippocampal gyrus, and the entorhinal cortex) with the amygdala, the hypothalamus, the nucleus accumbens (NACc), and the orbitofrontal cortex ${ }^{47}$ (- Fig. 1). The emotional circuits do indeed form a border or connection point between the neocortex (mediating external stimuli) and the hypothalamic and brainstem structures (mediating internal stimuli). ${ }^{38}$ Major pathways of the emotional system are demonstrated in -Fig. 2. The cingulate cortex is considered as the receptive cortical region regarding emotional stimuli. The cingulate cortex projects to the hippocampus, which then projects to the hypothalamus by the fornix to elicit behavioral, endocrine, and autonomic responses to emotional stimuli. ${ }^{49,64}$ The mammillary bodies receive afferent projections from the hippocampus via the fornix, and then project to the anterior thalamus nucleus to provide efferents to the cingulate gyrus. ${ }^{38}$ The hippocampal formation, located under the parahippocampal gyrus along the medial temporal lobe, is made up of the hippocampus, the dentate gyrus, and the subiculum. Its primary functions are learning, memory, and recognition of novelty. ${ }^{38}$ Afferents are from the entorhinal cortex, the septal nuclei (indirectly via the entorhinal cortex and directly via the fornix), the amygdala, supramammillary area of the hypothalamus, and the brainstem (raphe nuclei, locus coeruleus, and ventral tegmentum). ${ }^{99}$ The primary efferent projection of the hippocampal formation is the fornix. ${ }^{99}$ Ventrally to the foramen

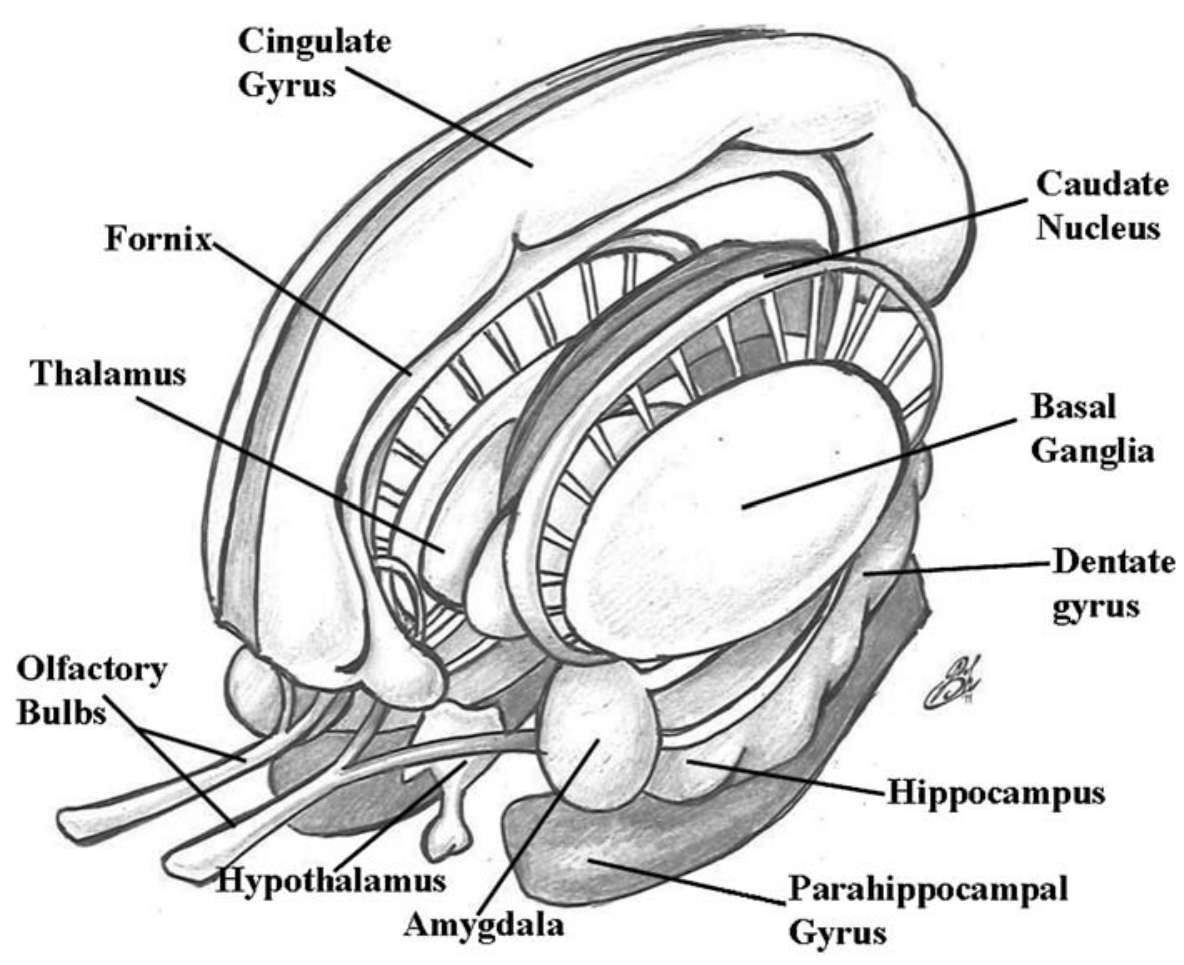

Figure 1 A drawing demonstrating the anatomy of the limbic system. 


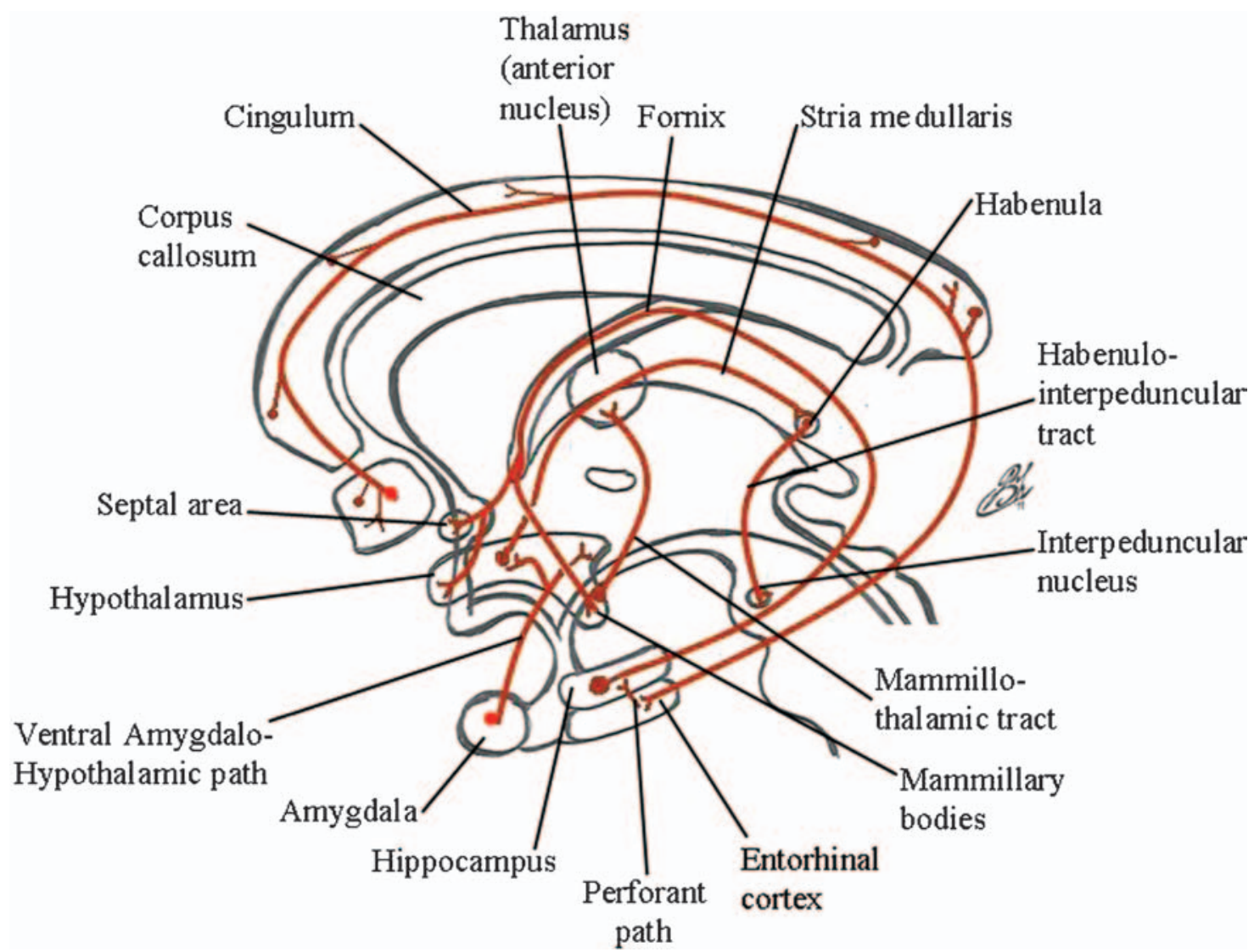

Figure 2 A schematic drawing demonstarting the major pathways of the limbic system.

Monro, the fornix divides at the anterior commissure into precommissural (projecting to septal nuclei) and postcommissural fibers (projecting to mammillary body, hypothalamus, septal region, medial frontal cortex, anterior thalamus, and tegmentum). The majority of fibers that enter the fornix originate in the subiculum, which in turn receives extensive input from the hippocampus and dentate gyrus. ${ }^{47}$ Damage to the hippocampus results in inability to convert recent memories into long-term memories and inability to store them. The amygdaloid complex is made up of several nuclei that are grouped into the basolateral (receive the lateral olfactory tract projections) and the corticomedial groups (receive indirect olfactory projections via the pyriform cortex). ${ }^{47}$ The largest input to the amygdala is from the insular cortex. Other afferents are from hypothalamus, hippocampus, thalamus, sensory association cortex, locus coeruleus, ventral tegmental area, and nucleus basalis of Meynert (nbM). The nbM provides the major efferent cholinergic projections to the amygdala and the cerebral cortex, thus it is important in the diffuse cortical activation and shows marked degeneration in Alzheimer's disease (AD). ${ }^{38}$ The primary efferents from dorsomedian amygdala travel via the stria terminalis to the anterior and ventromedian hypothalamus (VMH) and to the stria terminalis nuclei. The primary efferents from the basolateral amygdala travel via ventral amygdalofugal projections to the lateral hypothalamus (LH), septal region, mediodorsal thalamus (MD), and the nucleus of the diagonal band. ${ }^{99}$ Also, the amygdala projects to the neostriatum, ventral striatum, and cerebral cortex. Via these con- nections, the amygdala generates drive of activity and modulates endocrine activity, sexuality, reproduction, and autonomic responses. ${ }^{38}$ Bilateral destruction of the amyglada can produce the Klüver-Bucy syndrome (docility, hyperorality, and hypersexuality) and decreased conditioned fear response and decreased ability to recognize the meaningfulness of facial and vocal expressions of anger in others. ${ }^{64}$

\section{Hypothalamus}

The hypothalamus governs body homeostasis by modulating the activity of the autonomic nervous system, the endocrine system, and the limbic system. It also has a role in emotional behavior. Hypothalamic efferents reach the cortex via a relay in the anterior thalamic nuclei. ${ }^{99}$ The hypothalamic anatomy and function are demonstrated in - Fig. 3 .

\section{Frontal Lobe}

Although a simplified model, frontal lobe circuits can be divided into several groups ${ }^{55}$ :

1. The motor circuit: originates from the sensorimotor cortex and projects to the dorsal striatum. This pathway is involved in the mediation of somatic movement and converges on the basal ganglia.

2. Dorsolateral circuit: originates in the dorsolateral prefrontal cortex (DLPFC) and projects to the head of the caudate and medial putamen. This pathway influences behavior and personality and has executive responsibilities involving 


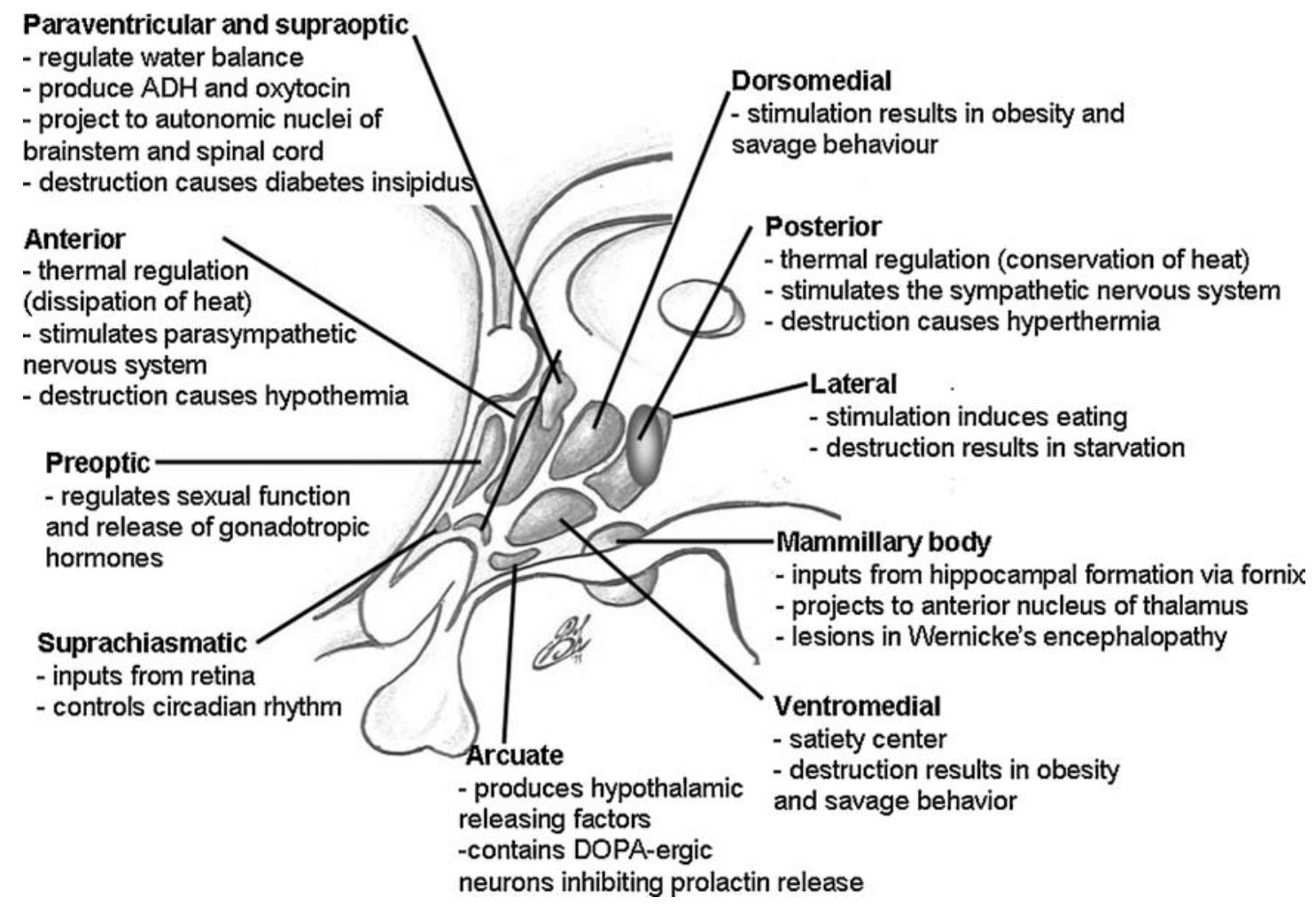

Figure 3 A drawing demonstrating the hypothalamic anatomy and function.

activities such as formulating plans, maintaining attention and concentration, and changing problem-solving strategies when needed. The dorsolateral prefrontal syndrome is characterized by impairment of executive functions, clinically evidenced by executive dysfunction such as perseveration.

3. Orbitofrontal circuit: originates in inferolateral prefrontal cortex and projects to the medial caudate nucleus and NAcc. This pathway is the center of the biological control of inhibition, emotions, and drive states. It is also part of the dopamine-driven reward circuit of the brain (especially NAcc) and it is activated in drug addicts. The orbitofrontal syndrome results in features that seem to have afflicted Phineas Gage as well as a countless number of lobotomy patients. These features include disinhibition, irritability, and lability. ${ }^{16}$

4. Anterior cingulate circuit: originates in the anterior cingulate gyrus and projects to the ventromedial striatum. This pathway forms a major cortical-limbic pathway. The anterior cingulate syndrome in its most dramatic manifestation results in akinetic mutism and profound apathy. ${ }^{7}$ These frontal lobe regions can be organized into two functionally related compartments: the associative dorsal compartment (DLPFC + lateral orbitofrontal cortex [LOFC]) and the limbic ventral compartment (cingulate + subgenual gyrus + medial orbitofrontal cortex [MOFC]). ${ }^{55}$

\section{Cortical-Subcortical Pathways}

The basal ganglia are the initial target for all frontal lobe circuits and an understanding of basal ganglia structure and function is essential. The basal ganglia comprise a complex processing system that interprets diffuse cortical signals in the striatum and returns information to the cortex through the globus pallidus, substantia nigra, and thalamus. The dorsal component is related with the associative loop. Most of the information in the dorsal compartment flows through central striatal regions, such as the head of the caudate and portions of the NAcc core. The primary cortical association of the limbic loop is the ventral component. Most of the information in the ventral component flows through ventromedial striatal regions, such as the NAcc core and the NAcc shell. ${ }^{55}$ It is important to note that lesions of basal ganglia structures within the frontal circuitry can give rise to disorders that resemble frontal lobe lesions themselves. Although not as prevalent or extensively studied, such "striatal syndromes" also exist in which disinhibition and executive dysfunction have been documented. ${ }^{14}$

The thalamocortical (TC) loop is thought to be the basic building block of behaviors that span from motor activity to psychiatric phenomena. Each TC loop consists of a specific region of cerebral cortex and its reciprocal excitatory connections with a specific target within the thalamus. In parallel with this direct, topographically organized TC activity is a circuit that involves the same regions of cortex and thalamus but is directed through the basal ganglia. ${ }^{55}$ The TC and the cortico-striato-thalamo-cortical (CSTC) loops and their association with the basal ganglia represent a pivotal area in which dysfunction can lead to disordered behavior. ${ }^{48}$ Furthermore, such an area provides a rich anatomic nexus to surgically modulate brain function. Thus, it stands to reason 
that these TC/CSTC loops are important when considering DBS for psychiatric disease. Evidence from functional neuroimaging and stereotactic lesioning procedures suggests that the most pertinent of the CSTC loops in psychiatric illness are the prefrontal and limbic loops. ${ }^{55}$ The dorsolateral prefrontal (associative) circuit involves the DLPFC and LOFC and their associated projections via the anterior internal capsule to the thalamus. This associative loop is believed to be integral to processes involving working memory, spatial memory, and executive function. It is thought to play a role generally in cognitive dysfunction, including patient insight about symptoms and ability to suppress negative feelings and painful stimuli across several psychiatric disorders. The psychomotor retardation of severe depression may also be a consequence of dysfunction of this circuit. ${ }^{55}$ The limbic loop consists mainly of the MOFC, the anterior cingulate, SCG, the agranular insular cortex and their associated projections via the anterior internal capsule to the caudate, and NAcc. Summary of the main TC/CSTC circuits within human brain is demonstrated in

-Fig. 4.

\section{Mechanisms of Treatment}

\section{VNS}

VNS is approved in the United States for treating chronic or refractory depression in patients not showing an adequate response after four antidepressant treatments. It works by having an electrode attached from a pacemaker implanted on the left side of the chest to the left vagus nerve in the neck. Although its mechanism of action remains unclear, it has been suggested that impulses from the vagus nerve are transmitted to the following regions: locus coeruleus, raphe nuclei, and nucleus tractus solitarius, which then project to other regions of the brain, ultimately affecting the limbic system. ${ }^{15}$ It is shown that parasubthalamic nucleus (PSTN) axons have massive projections to the region of a column of parasympathetic preganglionic neurons in the brainstem, starting in the salivatory region of the pons and proceeding caudally in the medial part of the nucleus of the solitary tract and in rostral and intermediate regions of the dorsal motor nucleus of the vagus nerve. ${ }^{31}$ The STN and PSTN also are related to dorsolateral regions of the parvocellular reticular

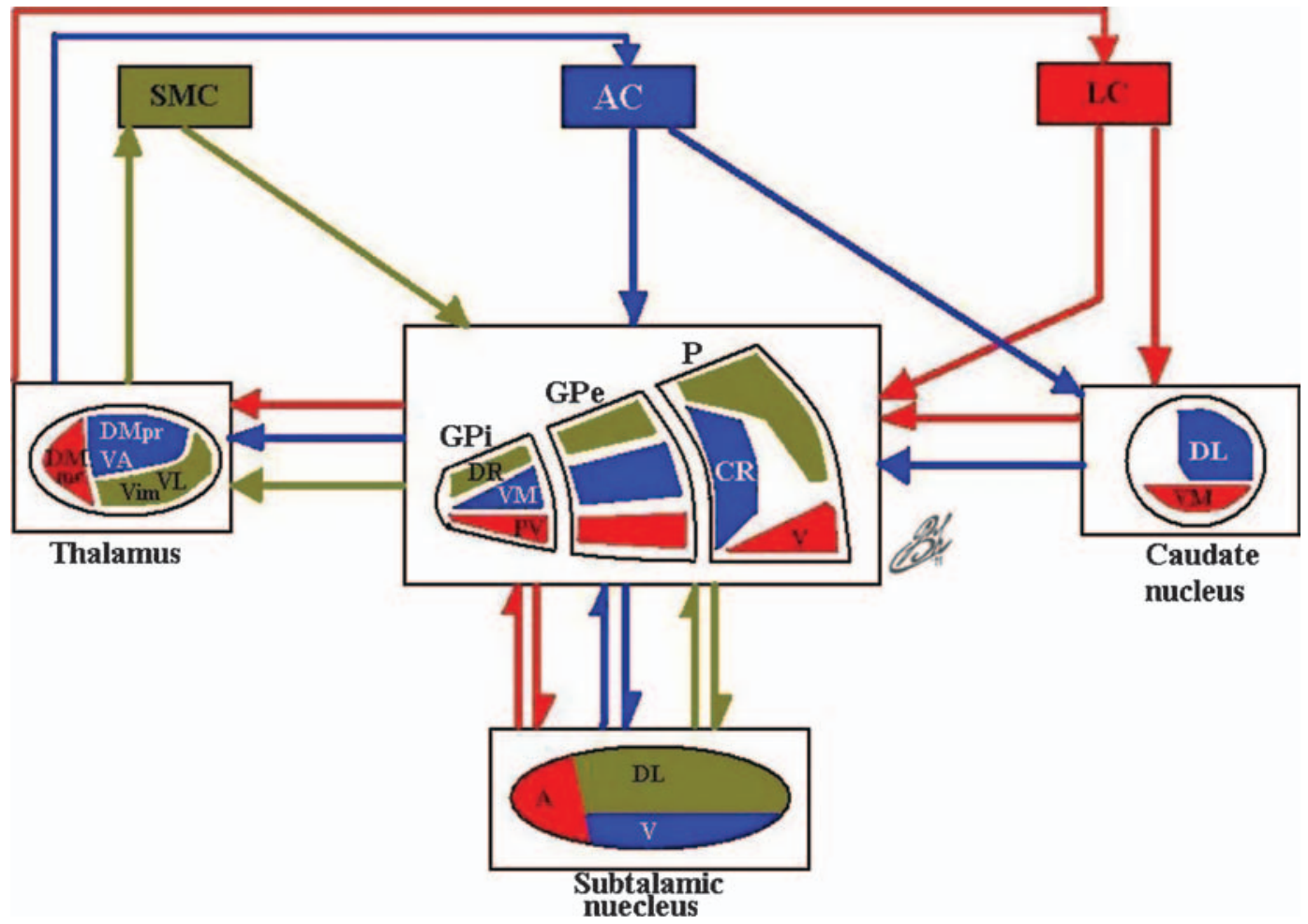

Figure 4 Schematic diagram illustrating the main cortico-striato-thalamo-cortical circuits within human brain. This figure shows an arrangement of the motor (green), associative (blue), and limbic (red) pathways. Neurons from the sensorimotor cortex project to the posterolateral putamen. The GPi is the primary output nucleus of the basal ganglia to the cortex via the ventrolateral thalamus. The associative circuit originates in the dorsolateral prefrontal and lateral orbitofrontal cortices, which project to the caudate nucleus and anteromedial portion of the putamen. From the striatum it projects to the dorsomedial region of the GPi and anteromedial parts of the GPe and STN to converge on the GPi and back to the cortex via the ventral anterior nuclei of the thalamus. The limbic circuit starts in the hippocampus, amygdala, and paralimbic and limbic cortices and projects to the ventral striatum (ventral portion of the caudate and putamen, including NAcc). The ventral striatum projects to the limbic portion of the GPe and medioventral STN and ventral GPi and to the cortex via the mediodorsal nucleus of the thalamus. A, anterior; AC, associated cortex; CR, centrorostral; DL, dorsolateral; DR, dorsorostral; DMpc, dorsomedial parvocellular; DMmc, dorsomedial magnocellular; GPe, globus pallidus externus; GPi, globus pallidus internus; LC, limbic cortex; PV, posteroventral; P, putamen; SMC, sensorimotor cortex; V, ventral; VM, ventromedial; VL, ventrolateral; Vim, ventro-intermedius; VA, ventroanterior. 
nucleus between the nucleus of the solitary tract and the nucleus ambiguus, along with the periambiguus region and a zone lateral to it where vagal fibers exit the brainstem. ${ }^{31}$ Also, more rostrally, the STN provides a sparse to moderate terminal field to ventromedial regions of the caudoputamen, and it extends into adjacent regions of the NAcc. This can explain the relation between the VNS and the effects upon the NAcc. ${ }^{69}$ Histological studies on animal models showed markedly increased c-fos expression in forebrain and brainstem regions. On the other hand, increased expression of cAMP response element-binding protein and decreased expression of FosB were seen in NAcc; both effects lead to increased motivation for natural rewards. ${ }^{69}$ These findings support the idea that VNS therapy acts directly by stimulating brainstem structures and indirectly by regulating the activity of neurons in limbic and cortical regions involved in mood regulation. ${ }^{52}$ Single photon emission computed tomography (SPECT) imaging studies after VNS showed increased regional cerebral blood flow (rCBF) in the left middle frontal gyrus (BA 46) and reduced rCBF in the hippocampus/amygdala, left caudate, dorsal brainstem, and other areas. ${ }^{126}$ Also, significant reductions in the right DLPFC, left SCG, bilateral ventral anterior cingulate, right dorsal anterior cingulate, bilateral amygdala, left hippocampus, right thalamus, left caudate, and the brainstem were found. ${ }^{126}$ Medial temporal findings included reduced $\mathrm{rCBF}$ in the amygdala and left hippocampus. These studies showed that VNS may be a less focal method of electrical stimulation. In fact, the lack of focality of this technique might be associated with the limited clinical results. It might also be used in combination with another focal method of brain stimulation. Many reports had shown good to moderate effects of VNS in the treatment of depression, ${ }^{15}$ migraine, ${ }^{11}$ obsessive-compulsive disorder (OCD) (by effects on NAcc and improving the dysfunction of the reward system in these patients), ${ }^{18} \mathrm{AD}$ (by stimulating the hypoactive locus coeruleus and the limbic circuit), ${ }^{86}$ and eating disorders (by modulating cortico-limbic circuits and eating centers). ${ }^{20}$ Therefore, VNS may be a promising form of treatment; however, the present evidence supporting its use is still limited.

\section{Ablative Surgery}

Many psychiatric disorders have some common symptoms and similar grouping, and may share similar pathological pathways. ${ }^{65}$ For this reason, these disorders may derive significant benefit from procedures targeting a common anatomical pathway. For example, anterior cingulotomy, which involves bilateral lesions to the anterior cingulate gyrus, thus severing the cingulum bundle, was reported to be significantly effective for the treatment of bipolar disorder (BD), depression, and schizoaffective disorder. ${ }^{65}$ Ablative techniques, including open microscopic resection, stereotactic electrode ablation, and frameless stereotactic radiosurgery, all shares the characteristic of being irreversible. Stereotactic electrode ablation is performed by radio frequency electrocoagulation and has the advantage of the ability of microelectrode recording and stimulation for the confirmation of the target location. Stereotactic radiosurgery is non- invasive, however, lacks the important electrophysiological confirmation of the target. ${ }^{28}$

\section{DBS}

The biological mechanisms of action remain unclear; three primary explanations have been proposed for the biological mechanisms of $\mathrm{DBS}^{122}$ : (1) it silences stimulated neurons, (2) it modulates neuronal network activity and neurotransmission, and (3) it induces long-term synaptic changes (plasticity). The first explanation is based on the observation that, functionally, DBS induces a similar therapeutic effect to that of a lesion of the stimulated area. Evidence for the second hypothesis has been provided by animal and imaging studies showing that DBS-evoked activity propagates throughout the associated neuronal network to modulate neuronal activity and neurotransmitter efflux in distal nuclei. The third has been inferred from the delayed time course of therapeutic effects of stimulation. It is thought that low-frequency stimulation (LFS) activates neurons, ${ }^{5}$ whereas high-frequency stimulation (HFS) results in neuronal inhibition. ${ }^{23}$ Extracellular recording revealed spontaneous activity caused by spindle wave generation. Immediately after HFS, spindle wave activity was seen to be abolished, as noted by the lack of neuronal activity. ${ }^{118}$ However, recent data show that the effects of HFS are complex, and can cause both inhibition and excitation. Tawfik et al $^{118}$ demonstrated that HFS elevates extracellular glutamate and adenosine levels, which was not inhibited by treatments that block axonally dependent exocytotic release of neurotransmitter from neurons. By contrast, NAcc HFS increases rhythmicity in the cortex, which could be beneficial for the treatment of OCD and depression. ${ }^{83}$ Other possible mechanisms of action for HFS DBS include local neuronal inhibition with concomitant activation of surrounding fibers, thus resulting in increased synaptic output and activation of afferent axon terminals. ${ }^{58}$ Recordings of local field potentials from the STN in patients with Parkinson's disease after neurosurgery showed strong increases in $\beta$ (15 to $30 \mathrm{~Hz}$ ) oscillatory activity in the STN when the patients were without dopaminergic medication, which were subsequently suppressed with both medication and therapeutic effective STN stimulation of more than $70 \mathrm{~Hz}{ }^{35}$ This suggests that some symptoms of Parkinson's disease might be linked to an abnormal and potentially deleterious synchronization of basal ganglia output in the $\beta$ frequency band of $\sim 20 \mathrm{~Hz} \cdot{ }^{35}$ It also strongly suggests that DBS stimulation could work through normalizing pathological oscillations and synchronization of neuronal subpopulations in the $\beta$ band in the closed loop networks involved in motor control. ${ }^{32} \mathrm{~A}$ hypothesis that takes into account all of these clinical observations is the hypothesis of jamming (i.e., overwriting of pathological activity by introducing a frequency that interferes with the pathological message). ${ }^{58}$ The local effects of stimulation on neuronal activity, in turn, affect the flow of information throughout the network. ${ }^{122}$ The delayed time course of therapeutic effects of stimulation indicates that sudden disruption of pathological network activity may provide only a minor component of the therapeutic mechanism of action. ${ }^{72}$ It has been hypothesized that DBS for neuropsychiatric 
disease has both short- and long-term components resulting from complementary but distinct mechanisms of action. Sudden symptom reprieve results from the immediate disruption of pathologic activity in cortico-striatal-pallido-TC circuitry, whereas enduring improvements occur only after long-term changes in synaptic effectiveness and/or connectivity have had time to take effect. ${ }^{72}$ Thus, the normalization of abnormal (hyper/hypo)metabolic changes may result from activity-dependent mechanisms that work together to mediate neuronal plasticity (including formation of new synapses, growth of new connections, and up- or down-regulation of information flow at the synapse). Over time, this may ultimately result in global changes in neuronal network processes that mediate the enduring therapeutic effects of DBS. ${ }^{72}$ However, clinical observation shows that symptoms relapse immediately within minutes if the impulse generator is switched off. These observations do not exclude synaptic plasticity caused by DBS but speak probably against fixed molecular changes. This indicates that the mechanism of DBS effect is more complicated and many aspects are not yet clear.

\section{Clinical Approach and Patient Selection}

All patients must be referred for surgical intervention by their treating psychiatrists. The referring psychiatrist must demonstrate ongoing commitment to the patient and the evaluation process and must also agree to be responsible for postoperative management. After meeting of the proper criteria, the patient undergoes a more detailed presurgical screening evaluation by an experienced multidisciplinary group of psychiatrists, neuropsychologists, neurosurgeons, and neurologists.

Although initially any patient with severe psychiatric illness was considered a candidate for surgical intervention, the current indications for psychosurgery are more restrictive. Assessment of psychosurgical candidacy requires that these mentioned criteria of chronicity, severity, disability, and treatment resistance be operationalized to form guidelines ${ }^{41,58,98}$ (-Table 1). The major psychiatric diagnostic group, as defined by the "Text Revision fourth edition of the Diagnostic and Statistical Manual of Mental Disorders"
(DSM-IV-TR), that might benefit from surgical intervention includes OCD and major affective disorders (unipolar major depression [MD] or BD) ${ }^{60}$ In many instances, patients present with mixed disorders combining symptoms of anxiety, depression, and $O C D$, and these patients remain candidates for surgery. Patients with schizophrenia, history of personality disorders, substance abuse, or other significant axis II symptomatology were routinely not considered ideal candidates for surgery, although, recent reports showed that properly selected patients of these groups gained benefit from surgical approaches. ${ }^{65}$ Patients with severe aggressive outbursts and the potential for serious self or others injury may be considered for surgical approaches. ${ }^{74,91}$

\section{Surgical Applications}

The most common surgical (ablative or DBS) targets for the treatment of psychiatric diseases are demonstrated in -Fig. 5. It must be remarked that these are experimental approaches for most indications.

\section{Major Depressive Disorder (MD)}

$\mathrm{MD}$ is one of the most disabling and common diagnoses throughout psychiatric disorders. It represents a current prevalence of 5 to $10 \%$ of the general population and up to 20 to $25 \%$ for the lifetime period. ${ }^{107}$ Neurobiological correlates of depressive illness can be grouped into the following three main components: cortical, subcortical, and limbic ${ }^{115}$ (-Fig. 6). The cortical component appears to give rise to the psychomotor and cognitive aspects of depressive symptoms and consists of the prefrontal cortex, the dorsal portion of the anterior cingulate gyrus, and areas of the premotor cortex. This cortical component has access to the striatum and then creates a feedback loop via the thalamus. The subcortical component involves the affective experiencing of depressive symptoms, including anhedonia and sadness. This aspect of the neural circuit includes, among others, SCG, orbitofrontal cortex, and limbic structures in the brain involved with negative emotions, including the NAcc and amygdala. This component also interacts with the striatum and subsequently the thalamus to create a loop. Brain imaging researches of

Table 1 Criteria for Assessment of Psychosurgical Candidacy

\begin{tabular}{|l|l|}
\hline $\begin{array}{l}\text { Criteria for Psychosurgery } \\
\text { Candidacy }\end{array}$ & Comment \\
\hline Chronicity & $\begin{array}{l}\text { Enduring nature of the illness without extended periods of symptomatic relief. The } \\
\text { preferred chronicity period is at least } 1 \text { year. Practically, confirmation of treatment } \\
\text { resistance usually requires more than } 5 \text { years. }\end{array}$ \\
\hline Severity & $\begin{array}{l}\text { Patient's illness is manifested in terms of subjective distress and decrement in } \\
\text { psychosocial functioning. This is usually measured using validate clinical research } \\
\text { instruments, such as Yale-Brown Obsessive Compulsive Scale, Beck Depression } \\
\text { Inventory score, or 17-item Hamilton Rating Scale for Depression. }\end{array}$ \\
\hline Disability & $\begin{array}{l}\text { Can be reflected, for example, by Global Assessment of Function scale and Minnesota } \\
\text { Multiphasic Personality Inventory. }\end{array}$ \\
\hline Treatment resistance & $\begin{array}{l}\text { Resistance to systemic trials of pharmacological, psychological, and, when appro- } \\
\text { priate, electroconvulsive therapy. }\end{array}$ \\
\hline
\end{tabular}



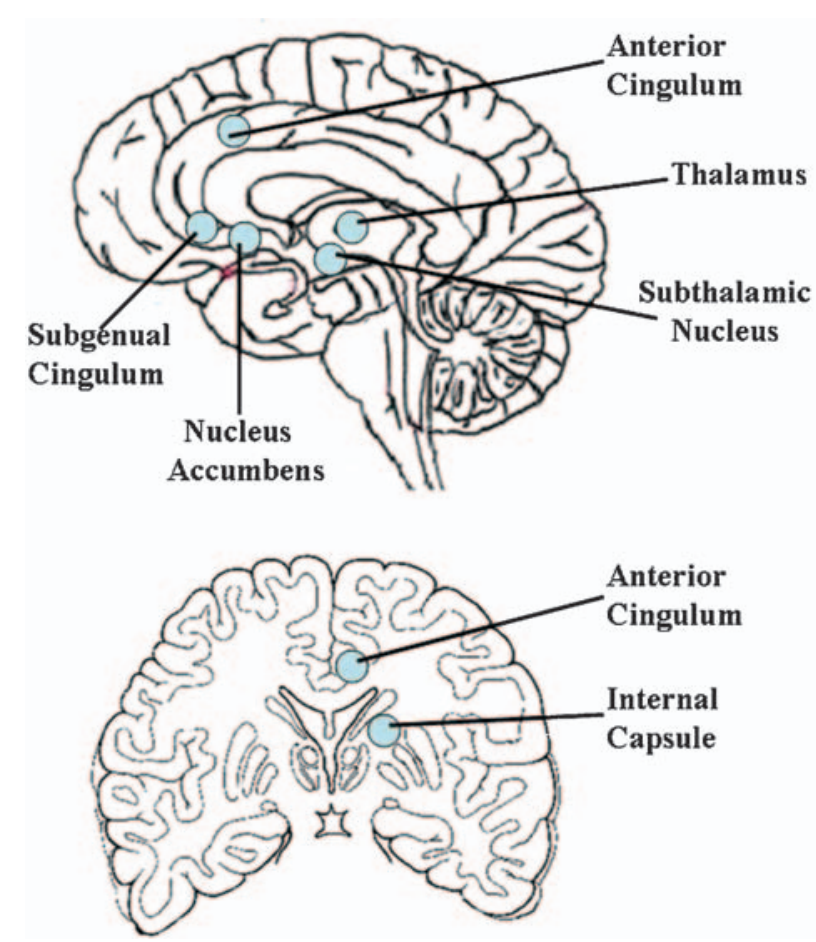

Figure 5 A schematic drawing demonstrating the common surgical (ablative or DBS) targets for the treatment of psychiatric diseases.

functional blood flow studies (positron emission tomography and functional magnetic resonance imaging) support depressive illness involving decreases in cortical regions activity with relative increases in limbic areas activity. ${ }^{97}$ The limbic component is thought that it regulates the cortical and subcortical circuits and includes the critical neuroendocrine aspects of depressive symptoms via inhibitory projections to these circuits. ${ }^{56}$ This "modulating pathway" involves the amygdala, the pregenual anterior cingulate cortex, and the hypothalamic-pituitary-adrenal axis.

Conventional treatment includes psychotherapy and many types of antidepressant drugs; however, over $60 \%$ of treated patients respond unsatisfactorily, and almost one-fifth becomes refractory to these treatments at long-term followup. $^{2}$ Therapy failure can lead to a life-threatening situation illustrated by the high number of suicides occurring in up to $15 \%$ of individuals. ${ }^{2}$ To identify the surgical candidate, patient must meet criteria for MD, must be in a current major depressive episode (MDE) as determined by the Structured Clinical Interview for DSM-IV Axis I Disorders-Patient Edition and have a minimum score of 20 on the Hamilton Rating Scale for Depression-17. ${ }^{82}$ Essentially, the inclusion criteria required duration of at least 1 year for the current MDE and treatment resistance as defined as failure to respond to a minimum of four different treatments, including antidepressant pharmacotherapy of sufficient dose and duration, evidence-based psychotherapy, and electroconvulsive therapy. ${ }^{82}$ In an open-controlled multicenter European study, successful response has been described in $53 \%$ of the patients, with complete remission in 33\%. ${ }^{113}$ VNS has shown low effectiveness rates immediately postoperatively and at short-term follow-up. ${ }^{113}$ However, its beneficial effect at long term in a substantial amount of patients, together with its low number of unwanted side effects, makes this
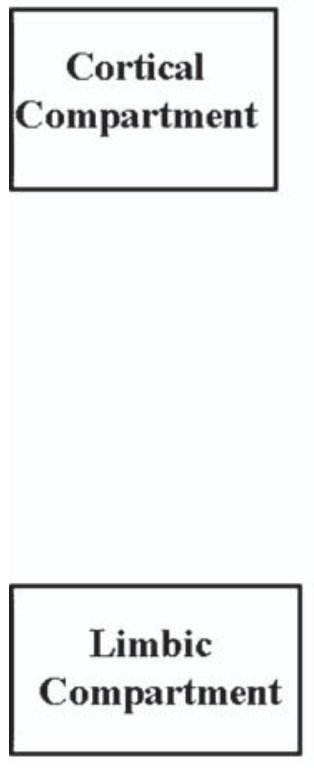

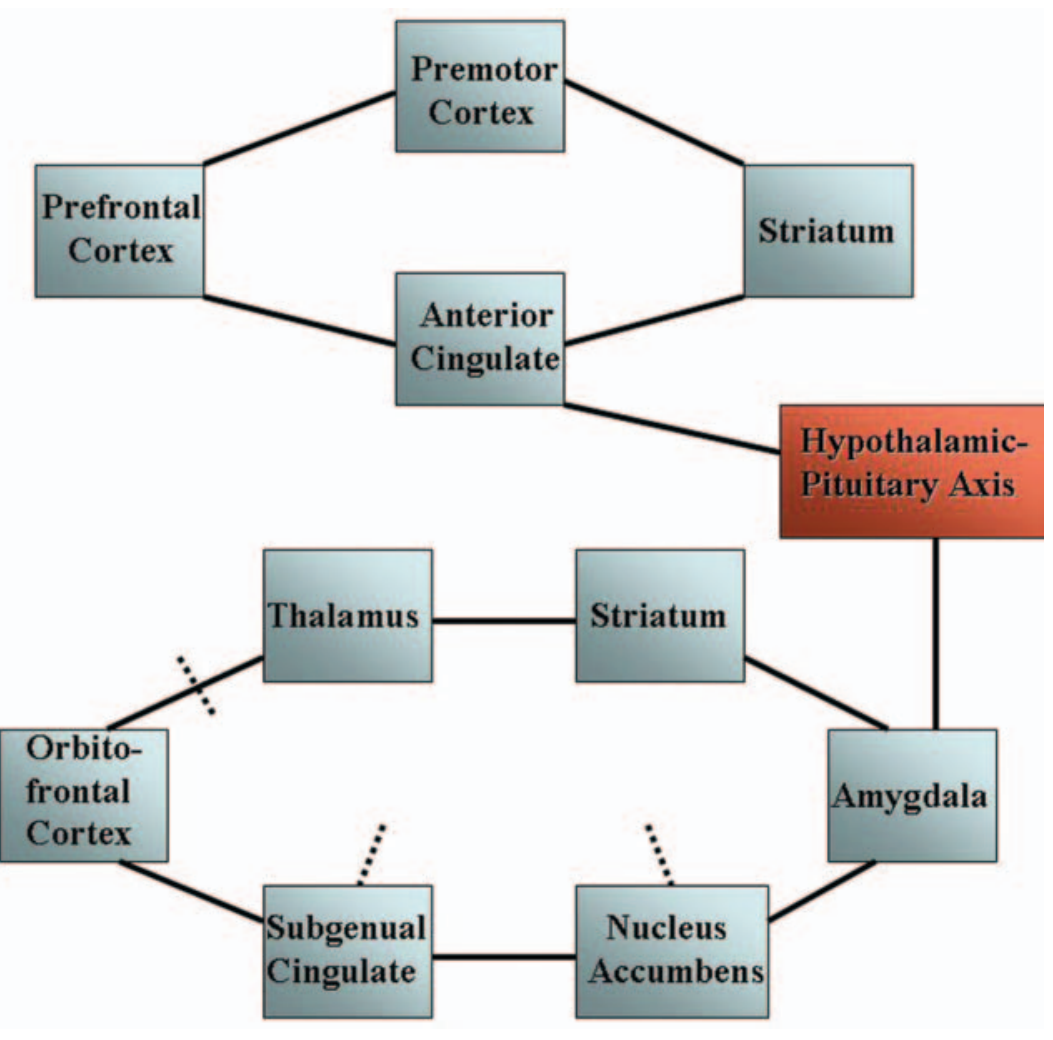

Figure 6 Neural circuitry of MD and DBS targets (dotted line). 
method an attractive treatment for patients suffering from MD. Ablative surgical procedures for the treatment of MD include lobotomy/leucotomy, orbital and cortical undercutting, cingulotomy, subcaudate tractotomy, and limbic leucotomy. In the literature review of Leiphart and Valone, ${ }^{65}$ cingulotomy was reported as being significantly more effective for the treatment of depression (77\% improvement) than frontal leukotomy alone (60\% improvement), frontal leukotomy combined with cingulotomy (69\% improvement), and subcaudate tractotomy (60 to $70 \%$ improvement). ${ }^{4}$ Nowadays, seven main DBS targets of interest are reported (-Table $\mathbf{2}$ ): SCG, ${ }^{68}$ NAcc, ${ }^{112}$ ventral caudate/striatum, ${ }^{76}$ inferior thalamic peduncle, ${ }^{45}$ lateral habenula, ${ }^{109}$ globus pallidus internus (GPi), ${ }^{57}$ and the cerebellum. ${ }^{37}$ Lozano et $\mathrm{al}^{70}$ reported DBS of SCG in 20 patients with MD. In this open label case series study, they proposed that the SCG may be able to act as a fulcrum to modulate the activity of both frontal cortex and limbic system and normalization of hyperactivity in the SCG may represent a marker of antidepressant response. ${ }^{81}$ In their case series, they reported that $60 \%$ cases responded to stimulation and $35 \%$ patients met criteria for remission. ${ }^{70}$ On the other hand, Malone et $\mathrm{al}^{76}$ reported $53.3 \%$ of cases responders to stimulation and $40 \%$ remission after ventral caudate/striatum DBS. It is also important to mention the case series of Heath et $\mathrm{al}^{37}$ in 1979, in which they treated six MD patients with cerebellar DBS. They reported that $83 \%$ of the patients showed significant improvement without necessity of postsurgery medication. ${ }^{37}$

\section{Bipolar Disorder (BD)}

$\mathrm{BD}$ is a complex disorder defined by the presence of mania (i.e., bipolar I disorder BD-I]) and hypomania (bipolar II disorder [BD-II]) alternating with depression. ${ }^{84}$ Compared with MD, BD seems to present with an earlier age of onset, more frequent episodes, lower probability of recovery, greater chronicity and illness duration, higher rate of suicidality, atypical features (e.g., hypersomnia), greater neurocognitive impairment, and suboptimal response to conventional antidepressant medications. ${ }^{84}$ The refractory nature of these symptoms and of depression, in particular, has led to research exploring a surgical solution to debilitating and resistant disease. The International Society for Bipolar Disorders Task Force recently defined treatment response of BD as $>50 \%$ improvement in the core DSM criteria for depression. ${ }^{121}$ Lipsman et $\mathrm{al}^{68}$ suggested that treatment-resistant BD, and therefore candidacy for DBS procedures, can be defined as a disease state that is nonresponsive to adequate trials of monotherapy with lithium or lamotrigine, as well as lithium or lamotrigine in combination with at least one anticonvulsant or antipsychotic drug. Although well established in MD, there are still no defined indications for surgery in BD and it is mainly regarded by the treating physician's own apprehension and individual evaluation of each patient's status. ${ }^{68}$ In treatment-resistant cases of $\mathrm{BD}$, VNS was found to have positive effect on the mood with documented good response of the patients. ${ }^{79}$ In a retrospective analysis using the subset of 25 patients with BD-I or BD-II diagnoses from a larger trial, the short- and long-term (up to 2 years) effects of VNS on bipolar and unipolar depression were similar. ${ }^{93}$ In a recent review of Leiphart and Valone ${ }^{65}$ of ablative psychosurgical treatments they evaluated patients of BD operated with cingulotomy or frontal leukotomy. Cingulotomy was reported as significantly more effective for the treatment of BD (85\% symptom free) compared with frontal leukotomy (33\% symptom free). Spangler et al ${ }^{116}$ published their results of their retrospective case series study after performing bilateral cingulotomies in five patients with BD; two patients were responders, two had a less significant improvement, and one did not respond to treatment. There were no long-term complications associated with the procedures. ${ }^{116}$ Recent studies indicate a hyperactivation of subcortical structures, specifically the SCG, in depressed patients that corrects after treatment with pharmacotherapy as well as DBS. ${ }^{30}$ This supports the existence of functionally coupled cortical-subcortical loops that govern mood and its alteration. The ability of patients who underwent SCG DBS to return to work, establish goals, and reassimilate into their families could represent this new ability to modulate their response to negative stimuli, both internal and external. In a prospective study, Bewernick et $\mathrm{al}^{9}$ used the NAcc as a target in 10 treatment-resistant depressed patients and achieved in 50\% significant reductions in depression scale scores at 1 -year

Table 2 Summary of DBS Targets for Depression and Outcomes

\begin{tabular}{|c|c|c|c|c|}
\hline Author & $\begin{array}{l}\text { No. of } \\
\text { Patients }\end{array}$ & Target & Study Type & Outcome \\
\hline Lipsman et al ${ }^{68}$ & 20 & Subcallosal gyrus & Open label & $\begin{array}{l}53 \% \text { response and } 40 \% \text { remission } \\
\text { in } \mathrm{HDRS}_{17}\end{array}$ \\
\hline Schlaepfer et al ${ }^{112}$ & 3 & Nucleus accumbens & Double blind & Mean $78 \%$ reduction in $\mathrm{HDRS}_{24}$ \\
\hline Malone et al $^{76}$ & 15 & Ventral caudate/striatum & Open label & $\begin{array}{l}53 \% \text { response and } 40 \% \text { remission } \\
\text { in } \mathrm{HDRS}_{24}\end{array}$ \\
\hline Jiménez et $\mathrm{al}^{45}$ & 1 & Inferior thalamic peduncle & Uncontrolled case study & $80 \%$ reductionin $\mathrm{HDRS}_{24}$ \\
\hline Sartorius et al ${ }^{109}$ & 1 & Lateral habenula & Uncontrolled case study & Total remission \\
\hline Kosel et $\mathrm{al}^{57}$ & 1 & Globus pallidus internus & Uncontrolled case study & $50 \%$ reductionin $\mathrm{HDRS}_{24}$ \\
\hline Heath et $\mathrm{al}^{37}$ & 6 & Cerebellum & Retrospective & $83 \%$ improvement (no scales) \\
\hline
\end{tabular}

DBS, deep brain stimulation; HDRS, Hamilton Depression Rating Scale. 
follow-up. In other open-label study by Malone et al, ${ }^{76} 15$ patients underwent DBS of the ventral caudate/striatum, with $40 \%$ achieving a remission at follow-up after more than 6 months. These results indicate that there may not be a single best target for surgical modulation, but instead several targets may exist along a dysfunctional corticostriato-thalamic loop.

\section{General Anxiety Disorder (GAD)}

GAD is the most commonly diagnosed anxiety disorder, wherein the patient's intensity, duration, or frequency of anxiety is far out of proportion to the actual likelihood or impact of a feared event. ${ }^{2}$ Compared with other anxiety disorders, GAD has chronic anxiety, oftentimes without provocation. ${ }^{2}$ Most of the surgically managed cases of GAD were treated by ablative means. ${ }^{65}$ Surgical treatment options were anterior callosotomy, cingulotomy, frontal leukotomy alone, frontal leukotomy combined with cingulotomy, and subcaudate tractotomy (innominatomy). Frontal leukotomies consisted of stereotactic focal lesions in the medial frontal lobe to interrupt frontothalamic and hypothalamic connections and did not consist of total frontal disconnection. ${ }^{65}$ Although only few patients underwent anterior capsulotomy, results from literature review suggested that anterior capsulotomy was significantly more effective for the treatment of GAD (91.6\% improvement) than cingulotomy (66.6\% improvement), anterior callosotomy (23\% improvement), and subcaudate tractotomy ( $41 \%$ improvement). ${ }^{65}$

\section{Obsessive Compulsive Disorder (OCD)}

OCD is a psychiatric illness in which intrusive thoughts or impulses (obsessions) generate anxiety that is relieved through the engagement in ritualistic or repetitive behaviors (compulsions). This is because performance of compulsions has an anxiolytic effect. OCD is relatively common, with a lifetime prevalence of 2 to $3 \%{ }^{103}$ Standard therapeutic options consist of selective serotonin reuptake inhibitors and cognitive behavioral therapy. ${ }^{43}$ However, 20 to $40 \%$ of patients with OCD have persistent symptoms leading to chronic functional impairment. ${ }^{95}$ Based on these findings, distinct neuronal circuits have been implicated in symptoms of OCD involving feedback loops between the cortex, striatum, and thalamus. A multicircuit hypothesis of OCD states that the primary pathogenic mechanism is a dysregulation of the basal ganglia and limbic striatal circuitry working in concert with portions of the orbitofrontal and anterior cingulate cortex. Simplified, one can postulate the following three components to this model (- Fig. 7) ${ }^{115}$ : (1) The excitatory cortico-thalamic pathway via the anterior limb of the internal capsule (ALIC). (2) The inhibitory CSTC loop serves as a counterweight to the excitatory positive feedback loop. (3) The component linking portions of the limbic circuits. These connections are hypothesized to contribute to the affective anxiety component of OCD symptoms. Bringing together these three components of the circuit, OCD symptoms occur when there is an abnormal positive feedback in the orbitofronto-thalamic circuit (\# 1 ), that is, in turn, inadequately inhibited or modulated by the

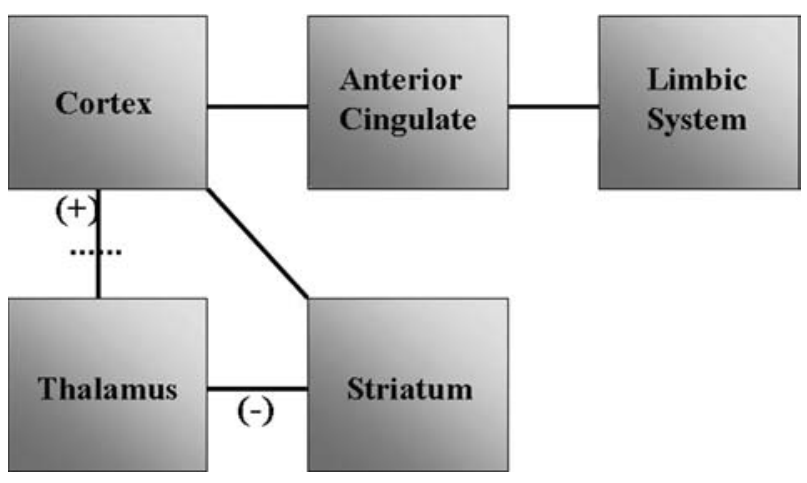

Figure 7 Neural circuitry of obsessive compulsive disorder and DBS target (dotted line).

CSTC loop (\# 2). One would then expect OCD symptoms to appear when the CSTC loop is abnormally decreased (too little inhibition), or when orbitofronto-thalamic activity is abnormally increased (too much excitation). From a therapeutic standpoint, increasing activity of the CSTC loop or decreasing activity of the orbitofronto-thalamic loop would be expected decreasing symptoms of OCD. Lastly, decreasing activity in the limbic component of the circuit (\# 3) would decrease the distressing negative affects associated with obsessions. ${ }^{115}$ Indications for the surgical treatment include verifying the diagnosis of OCD. Also, the OCD must have been present for at least 5 years and patients must have been treatment resistant, defined as less than 35\% improvement on the Y-BOCS after the different medical treatment regimens and complete cognitive-behavioral psychotherapy. ${ }^{42}$ Surgical ablative techniques include: anterior capsulotomy, anterior cingulotomy, frontal or limbic leukotomy, and subcaudate tractotomy. ${ }^{65}$ However, clinical results were found to be more effective with anterior capsulotomy than with the other methods, ${ }^{65,87}$ with an improvement rate ranged between 64 and $73 \%$.

Greenberg et $\mathrm{al}^{33}$ recently reviewed the combined longterm results from four centers in which the VC/VS target is used. Response rates improved as the target was shifted posteriorly, to within a millimeter of the posterior border of the anterior commissure, as the fiber bundle being targeted grows more compact as it courses posteriorly. ${ }^{66}$ The refinement in target selection was attended by an increase in the percentage of patients manifesting $\geq 35 \%$ reductions in Y-BOCS scores (from 33 to 75\%). As the inferior anteromedial STN receives limbic and associative cortical input via CSTC circuits originating in the $\mathrm{OFC},{ }^{44}$ Mallet et $\mathrm{al}^{75}$ reported YBOCS score reductions of $25 \%$ or more in $75 \%$ of patients with OCD after anteromedial STN DBS. However, there were several serious adverse events, resolved either spontaneously or promptly with adjustment of stimulator settings. ${ }^{75}$ Electrical stimulation of the inferior thalamic peduncle (ITP) could reduce OCD symptoms via effects propagated along the OFC and ventromedial striatum projections entering the thalamus. Jiménez-Ponce et $\mathrm{al}^{44}$ stimulated the ITP bilaterally, documenting Y-BOCS score reductions of at least 35\% as well as dramatic global assessment of function increases in all 
Table 3 Summary of DBS for Obsessive-Compulsive Disorder and Outcomes

\begin{tabular}{|l|l|l|l|l|}
\hline Author & $\begin{array}{l}\text { No. of } \\
\text { Patients }\end{array}$ & Target & Study Type & Outcome \\
\hline Greenberg et $\mathrm{al}^{112}$ & 26 & VC/VS & $\begin{array}{l}\text { Crossover double-blind } \\
\text { multicenter }\end{array}$ & $\begin{array}{l}35 \% \text { reduction in Y-BOCS in 70\% of } \\
\text { patients }\end{array}$ \\
\hline Mallet et al $^{75}$ & 18 & Anteromedial STN & $\begin{array}{l}\text { Crossover double-blind } \\
\text { multicenter }\end{array}$ & $\begin{array}{l}25 \% \text { reduction in Y-BOCS in 75\% of } \\
\text { patients }\end{array}$ \\
\hline Jiménez et al $^{44}$ & 5 & $\begin{array}{l}\text { Inferior thalamic } \\
\text { peduncle }\end{array}$ & Open label & $35 \%$ reduction in Y-BOCS \\
\hline Huff et al & Unilateral NAcc & $\begin{array}{l}\text { Double-blind sham-controlled } \\
\text { crossover }\end{array}$ & 25\% reduction in Y-BOCS \\
\hline
\end{tabular}

DBS, deep brain stimulation; VC/VS, ventral capsular/ventral striatal; Y-BOCS, The Yale-Brown Obsessive Compulsive Scale; STN, subthalamic nucleus; NAcc, nucleus accumbens.

patients. Moreover, Huff et $\mathrm{al}^{42}$ performed unilateral NAcc DBS in 5 patients with OCD and reported good results with at least a $25 \%$ reduction in their Y-BOCS OCD symptom scores after 1 year. Studies and clinical results of DBS in OCD are summarized in - Table 3.

\section{Tourette's Syndrome (TS)}

TS is a neuropsychiatric disorder characterized most prominently by childhood onset of changing motor and vocal tics. ${ }^{88}$ The tics are typically rapid, stereotyped movements, and/or vocalizations and many resolve completely by the late teens. Motor tics typically involve the face, head, and upper body. Vocal tics include grunting, sniffing, or barking that are associated with contractions of the oropharynx and diaphragm. ${ }^{88}$ For many TS patients their tics will remit after adolescence. However, in a significant number of patients, tics persist into adulthood and for some, they become disabling. Embarrassment from the tics can result in social isolation and failed relationships. ${ }^{117}$ Severe motor tics can be quite painful and result in joint dislocation, cervical radiculomyelopathy, and fractures. ${ }^{102}$ The basal ganglia and related CSPTC pathways are thought to mediate the pathophysiology of TS. ${ }^{94}$

It is hypothesized that patients with TS may have disinhibition of afferent TC signals or impaired inhibition at the cortical level. This disinhibition of excitatory neurons in the thalamus may, for example, result in the hyperexcitability of cortical motor areas and production of tics. ${ }^{14}$ Target sites included the frontal lobe (prefrontal lobotomy and bimedial frontal leucotomy), the limbic system (limbic leucotomy and anterior cingulotomy), the thalamus, and the cerebellum. ${ }^{1,114,119}$ Combined ablative approaches have also been tried, such as anterior cingulotomies plus infrathalamic lesions. The studies indicated that no single approach showed to be superior in the treatment of TS. ${ }^{119}$ Moreover, the results have often been unsatisfactory, or major adverse effects such as hemiplegia or dystonia have occurred.

Indications for the surgical treatment by DBS in TS include the following ${ }^{88,89}$ : confirmed diagnosis of TS by strict DSM-IV criteria; a Yale Global Tic Severity Scale (YGTSS) of $\geq 35 / 50$ for at least 12 months and the motor tic subscore $\geq 15$; age $\geq 25$ years to ensure a stable degree of severity and low probability of spontaneous improvement; failed trials of medications from 3 different classes: an $\alpha$-adrenergic agonist, dopamine antagonists, and a benzodiazepine, if the tic is focal, failed trial of botulinum toxin treatment; patients who do not have head banging tics that would damage the stimulation hardware.

Implantation of electrodes in three target areas have proved to be effective: the centro-median-parafascicular (CM-PF) complex of the thalamus, ${ }^{36}$ the internal segment of the GPi, ${ }^{1,80}$ and the ALIC. ${ }^{24}$ The greatest experience in the DBS treatment of TS has been assembled in the thalamus; internal ventro-oral nucleus, centromedian nucleus, and parafascicular nucleus. In a large open prospective study involving 18 patients treated with thalamic DBS, the average improvement rate for tic symptoms was around $70 \%$, as measured using the most frequently employed scale, the YGTSS. ${ }^{114}$ Recently, the same group published the 24-month results of 15 of the 18 patients, documenting continued amelioration of the symptoms. ${ }^{100}$ Martínez-Fernández et $\mathrm{al}^{80}$ targeted the posteroventral and anteromedial subregions of $\mathrm{GPi}$, and documented responses of 54 and $37 \%$, respectively. On the other hand, Flaherty et $\mathrm{al}^{24}$ performed ALIC stimulation in a single case and reported $25 \%$ decrease in YGTSS. Studies and clinical results of DBS in TS are summarized in - Table 4.

\section{Severe Aggressive Behavioral Disorders}

Intermittent explosive disorder (IED) is a psychological illness characterized by episodes of impulsive aggression that are disproportionate to the provocation. ${ }^{12}$ The root of such behavior involves a disturbance to the emotional circuitry of the brain. ${ }^{17}$ Almost all patients with IED have brain damage, which is usually traumatic in nature and occurs in the right frontobasal cortex. This damage is associated with a reduction in serotonin binding in the region. ${ }^{25}$ Mpakopoulou et $\mathrm{al}^{91}$ described current perspectives on amygdalotomy. In their literature review they determined improvement rates of aggression after bilateral amygdalotomy between 60 and $85 \% .{ }^{91}$ In a retrospective study, Kim et al $^{51}$ reported longterm follow-up of two patients with aggressive disorders in which they performed bilateral stereotactic amygdalotomy and subcaudate tractotomy. They found a decline in the Overt 
Table 4 Summary of DBS Targets for Tourette's Syndrome and Outcomes

\begin{tabular}{|l|l|l|l|l|}
\hline Author & No. of Patients & Target & Study Type & Outcome \\
\hline Porter et al $^{100}$ & 18 & CM-PF & Open prospective & 70\% reduction in YGTSS \\
\hline Martínez-Fernández et al & 5 & $\begin{array}{l}\text { Posteroventral GPi } \\
\text { Anteromedial GPi }\end{array}$ & Open label & $\begin{array}{l}\text { Posteroventral GPi: } 54 \% \\
\text { reduction in YGTSS } \\
\text { Anteromedial GPi: } 37 \% \\
\text { reduction in YGTSS }\end{array}$ \\
\hline Flaherty et al $^{24}$ & 1 & ALIC & Uncontrolled case study & 25\% reduction in YGTSS \\
\hline
\end{tabular}

DBS, deep brain stimulation; CM-PF, centro-median-parafascicular complex; YGTSS, Yale Global Tic Severity Scale; GPi, globus pallidus internus; ALIC, anterior limb of internal capsule.

Aggression Scale scores at 2-week and 7-year follow-up visits from 8 to 2, with improvement in social behavior. ${ }^{51}$ DBS of the posterior hypothalamus has also been described in case reports as a means of controlling intractable aggressive disorders, and showed complete elimination of selfmutilation. ${ }^{62}$ Based on the main role of the orbitofrontal cortex in generating explosive episodes, recently Maley et $\mathrm{al}^{74}$ performed DBS targeting the orbitofrontal projections to the hypothalamus in a woman. Although results lacked immediate improvement, after 2 years the patient reported absence of violent outbursts or physical altercations with marked socialization without the need of any sedation or antipsychotic drugs. ${ }^{74}$

\section{Schizophrenia}

Schizophrenia is characterized by symptoms including hallucinations, delusions, disorganized thoughts, incoherent speech, neglected personal hygiene, and disrupted cognitive and social abilities among others. Psychosurgery of schizophrenia is still performed on the ablative basis. However, in cases of uncontrollable violent behavior in schizophrenic patients DBS of the posterior hypothalamus may show clinical improvement of the symptom of aggression. ${ }^{26}$ There was a statistically significant difference in reported outcomes based on the stereotactic procedure performed for schizophrenia. Patients having cingulotomy had the best reported outcomes (56.5\% response), followed by anterior callosotomy (48.5\% response). ${ }^{65}$ Significant improvement was not seen after frontal leukotomy and subcaudate tractotomy. However, the best reported outcome for cingulotomy was poor in comparison with the other disorders. ${ }^{65}$

\section{Substance Addiction}

Addiction or substance dependence is a chronic relapsing disease characterized by a strong psychological and physical dependence, resulting in a withdrawal syndrome when use of the drug is stopped. ${ }^{71}$ Functional imaging studies have shown that, when an individual takes a psychoactive substance, dopamine is released in the NAcc, which causes "the high" state. ${ }^{54,71}$ By an increased dopamine release in the NAcc, the inhibition of the output neurons is decreased, which causes activation of the reward system. ${ }^{54}$ However, although that the mesolimbic dopaminergic system activation causes reward behavior and the dopaminergic system is considered an indicator for reward, the exact mechanism is still not clear. The feeling of well-being produced by activation of the reward system can be seen as positive reinforcement. Negative reinforcement involves escaping from or avoiding withdrawal symptoms, which occur after cessation of the substance use. ${ }^{54}$ Impairment of inhibitory control and decision making is seen due to the dysfunction of the dopaminergic neurotransmission system in the prefrontal cortex and the anterior cingulate gyrus. ${ }^{54,71}$ Procedures such as cingulotomy, hypothalamotomy, and resection of the substantia innominata and NAcc had been described as a treatment for severe addictive disorders. Medvedev et $\mathrm{al}^{85}$ investigated the long-term effects of bilateral cryocingulotomy in 348 patients with strong heroin dependence. After 2 years, $45 \%$ of the 187 patients interviewed had completely abstained from drugs and $17 \%$ were in remission for $>2$ years after 1 or 2 instances of drug taking in the past. In 13\% there was a partial improvement and $12 \%$ showed no change. Kerr and Pozuelo ${ }^{50}$ performed stereotactic hypothalamotomy (of the ventromedial nucleus) unilaterally or bilaterally and it seemed to help the patients regain their self-control. All patients showed a reduction in sexual drive. In patients who underwent bilateral hypothalamotomy, most suffered from severe side effects: lack of impulse, amnestic syndrome, vision disorder, and vegetative crisis were reported. The only report of resection of the substantia innominata for the treatment of addiction was described by Knight. ${ }^{53} \mathrm{He}$ reported good outcomes of the patients, however, he did not explain logic of this target choice and there was no information given about patient characteristics and no details were provided about the outcome. Gao et $\mathrm{al}^{29}$ reported stereotactic bilateral ablation of the NAcc to treat addiction. This would prevent craving for drugs after detoxification and in this way cause reduction in the relapse rate. He reported $25 \%$ complete recovery, 35.7\% relapse after 6 months, and 19.2\% of memory loss. In a recent review of Leiphart and Valone, ${ }^{65}$ it was found that all ablative procedures had similar treatment results. Bilateral NAcc DBS for drug addiction have been extensively studied in animal models with favorable results. ${ }^{40}$ However, there are only few anecdotal preliminary reports on NAcc DBS for addiction in humans. ${ }^{39,59,92}$ These reports showed disappearance of craving behavior immediately after NAcc stimulation. Most of the patients remained completely abstinent in the 1-year follow-up period, and 
alcohol consumption was reduced considerably in the rest. In a patient who received DBS for the primary purpose of alleviating severe anxiety and depression, stimulation in the NAcc had the unintended consequence of improving the patient's comorbid alcohol dependence. ${ }^{61}$ The rate of abstinence was $20 \%$ after 1 year and 30\% after 2 years. ${ }^{39,61,92}$ Interestingly, animal experiments showed that STN DBS can treat cocaine addiction and craving in rats without diminishing the motivation for other more naturally rewarding activities. ${ }^{104}$ According to these findings, behavioral addictions and addiction to dopaminergic drugs in Parkinson's disease (PD) patients with a dopamine dysregulation syndrome can be improved by STN DBS, leading to marked decreases in dopaminergic medications. ${ }^{120}$

\section{Eating Disorders}

The LH has long been implicated in feeding behavior and energy expenditure. Its role in appetite regulation was well described in early studies of LH lesioning, which induced leanness. ${ }^{3}$ Stereotactic electrocoagulation of the LH in obese humans was performed safely more than 30 years ago, resulting in significant, although transient, appetite suppression, and slight weight reduction. ${ }^{101}$ DBS stimulation of the LH was tested exclusively in animals. It was shown that HFS resulted in weight loss without changes in eating frequency, while LFS resulted in less eating frequencies and early satisfaction resulted in weight loss. ${ }^{108}$ Recently, Welkenhuysen et $\mathrm{al}^{124}$ induced an animal model of anorexia by LH stimulation. VMH has also been implicated in appetite regulation and the maintenance of energy homeostasis. Lesions of the VMH have been shown to induce weight gain in obese animals and lesions resulted in substantially more carcass lipid and hyperinsulinemia in rats. ${ }^{13}$ LFS of VMH inhibited feeding in hungry rats and eating resumed once the stimulation was terminated. Other effects of stimulation included fear, aversion, restlessness, and attempts at escape, which may have partially accounted for the decreased feeding behavior in these animals. ${ }^{105}$ Heightened metabolism induced by VMH stimulation was sustained by utilization of fat stores, most likely due to noradrenergic turnover. ${ }^{105}$ The NAcc is integral to the modulation of reward sensation shown to be associated with palatability of foods. Inhibition of NAcc resulted in dopamine depletion with significant attenuation of food hoarding and weight loss due to its effect upon the rewarding system, and resulted also in a concomitant smoking cessation in a reported case. ${ }^{78}$ Also, leukotomy was found to have an effect in the treatment of anorexia, however, it is not proposed as a surgical option in resistant case. ${ }^{90}$

\section{Persistent Vegatative State (PVS)}

PVS is defined as a degree of consciousness after severe brain injury whereby a patient has developed wakefulness with some degree of sleep-wake cycling but without any demonstration of environmental awareness. ${ }^{73}$ These patients have a functional brainstem and various dispersed "islands" of dysfunctional cortex. ${ }^{73}$ There is an important role of the intralaminar nuclei in maintaining attention and memory based upon their anatomical neural connections. A specific type of thalamic neuron thought to be involved in the more basic function of activating cortical networks. ${ }^{46}$ More recent research has demonstrated that such neural connections between the central lateral nuclei and the cortex are reciprocal and that these nuclei are densely innervated by brainstem arousal systems as well. ${ }^{111}$ Patients with specific ischemic infarctions of these nuclei primarily demonstrated disturbances in attention and subsequent SPECT imaging revealed decreased blood flow to the frontal cortices. ${ }^{123}$ It was found that stimulation of the frontocortical-striatopallidal-TC mesocircuit activates the frontal cortex with the aim of improving consciousness, awareness, or cognitive skills. ${ }^{110}$ The most recent series study was performed by Yamamoto and Katayama $^{125}$ in a total of 21 patients targeting CM-PF complex and mesencephalic reticular formation; eight patients improved in ability to obey verbal commands. Despite the large number of patients in the more recent trials, this study was limited by the timing of DBS therapy within the accepted 1-year time frame of spontaneous recovery. Recently, Schiff et $\mathrm{al}^{110}$ reported that a case was diagnosed as a minimally conscious state 6 years after a traumatic brain injury. Before DBS stimulation, the patient demonstrated visual pursuit and intermittently followed simple commands. ${ }^{110}$ After DBS implantation and therapy, they reported improvements in level of arousal (sustained eye opening, head turning to voices), functional limb movements, ability to feed orally, and 66\% improvement in the JFK Coma Recovery Scale-Revised score despite a 6-year history of minimal consciousness. The patient was soon able to name objects, move objects with his hands, and feed himself.

\section{Alzheimer's Disease (AD)}

$\mathrm{AD}$ is the most common form of dementia and is characterized by a progressive disturbance in cognitive function, with memory being particularly affected. Various pathological processes, including the deposition of fibrillar forms of amyloid $\beta$ protein, neuronal degeneration, synaptic loss, defects in neurotransmission, and disruption of neural network activity, have been implicated as possible contributors to the dysfunction. ${ }^{96}$ There is also losing the expected deactivation and toggling of the default network during cognitive tasks. ${ }^{96}$ VNS had been shown to have a positive effect on cognition in the form of motor speed, psychomotor function, language, and executive functions after stimulation. ${ }^{106}$ In a pilot study by Merrill et $\mathrm{al}^{86}$ they reported $17 \mathrm{AD}$ patients followed-up after VNS. After 12 months, 7 patients (41.2\%) improved and 12 patients $(70.6 \%)$ did not worsen. Behavior and mood disturbances, usually associated with disease progress, were not seen. Instead, modest improvements in mood and quality-of-life variables were found. They also found that median change in cerebrospinal fluid tau at 1 year was a reduction of $4.8 \%$, with $5.0 \%$ increase in phosphotau.

The importance of the fornix in memory function is supported by the observation that lesions in the fornix in experimental animals and humans are well known to produce memory deficits. ${ }^{10}$ Laxton et $\mathrm{al}^{63}$ hypothesized that it might be possible to use DBS of the fornix to drive its activity and to modulate the circuits mediating memory function in 
patients with impairments in this domain. Hamani et $\mathrm{al}^{34}$ recently reported that the possibility of modulating memory in a patient with obesity using DBS of the fornix and ventral hypothalamus provoked reversible memory phenomena with acute high-intensity stimulation. DBS has effects on brain areas that closely overlap with the brain default mode network (-Fig. 8). Recently, the Toronto group leaded by A. M. Lozano reported the preliminary phase I results of DBS stimulation of the anterior fornix in 6 patients with AD after 1 year of follow-up. ${ }^{63}$ They documented 4.2 increase in the mean AD Assessment Scale, Cognitive Subscale. The results are promising and final results are waited to be published.

\section{Ethical Considerations}

Ethical issues need to be considered. Although DBS is a nonablative procedure, it is not automatically ethical when applied to psychiatric illnesses. Despite some success, there remains considerable controversy about the indications of psychosurgery. The ultimate aim of surgery for intractable psychiatric illnesses is the same as for neurological disorders: to improve the quality of life of patients and their families. ${ }^{67}$ This goal has mostly been reached in DBS for PD, tremor and dystonia, and surgery in disabling neurological disorders is an accepted treatment. There is an urgent need for treatment alternatives for patients with psychiatric disorders. Psychiatric disease is common and can incapacitate a substantial proportion of patients, sometimes leading even to suicide. Surgical alternatives are beginning to become available for carefully selected patients. ${ }^{67}$ Clinical trial methodology in psychiatric neurosurgery differs significantly between centers; however, it is crucial that ethical principles remain universal. Although recent efforts have been made, there are currently no established ethical guidelines, universally applied, that govern the development and monitoring of psychosurgery trials. ${ }^{67}$ Indeed, such surgeries and trials are ongoing globally and in some academic centers, with very little information provided of the details of ethical approval and oversight. Lipsman et $\mathrm{al}^{67}$ had identified several criteria that can help to standardize ethical guidelines governing clinical trials in psychiatry neurosurgery (-Table 5). Currently, few psychiatric diseases meet these criteria. Those that do, such as OCD and MD, have undergone multiple pilot studies that have demonstrated safety and clinical efficacy and are now being explored in randomized, double-blind trials in centers globally. Psychosurgery remains experimental and efforts need to be put into organizing controlled studies. However, this expanding and promising field requires ongoing input from, and interaction between, basic and clinical sciences.

\section{Conclusion}

Recent advancements in psychosurgery reflect the affectivity and the increased popularity of this treatment model. This progression will aid to regain the place of psychosurgery as a standard neurosurgical practice. Also, the advancements in surgery are paralleled with the continuous progression in the knowledge of neuroscience. It is now clear that neurosurgeons need, more than ever, to establish their knowledge and

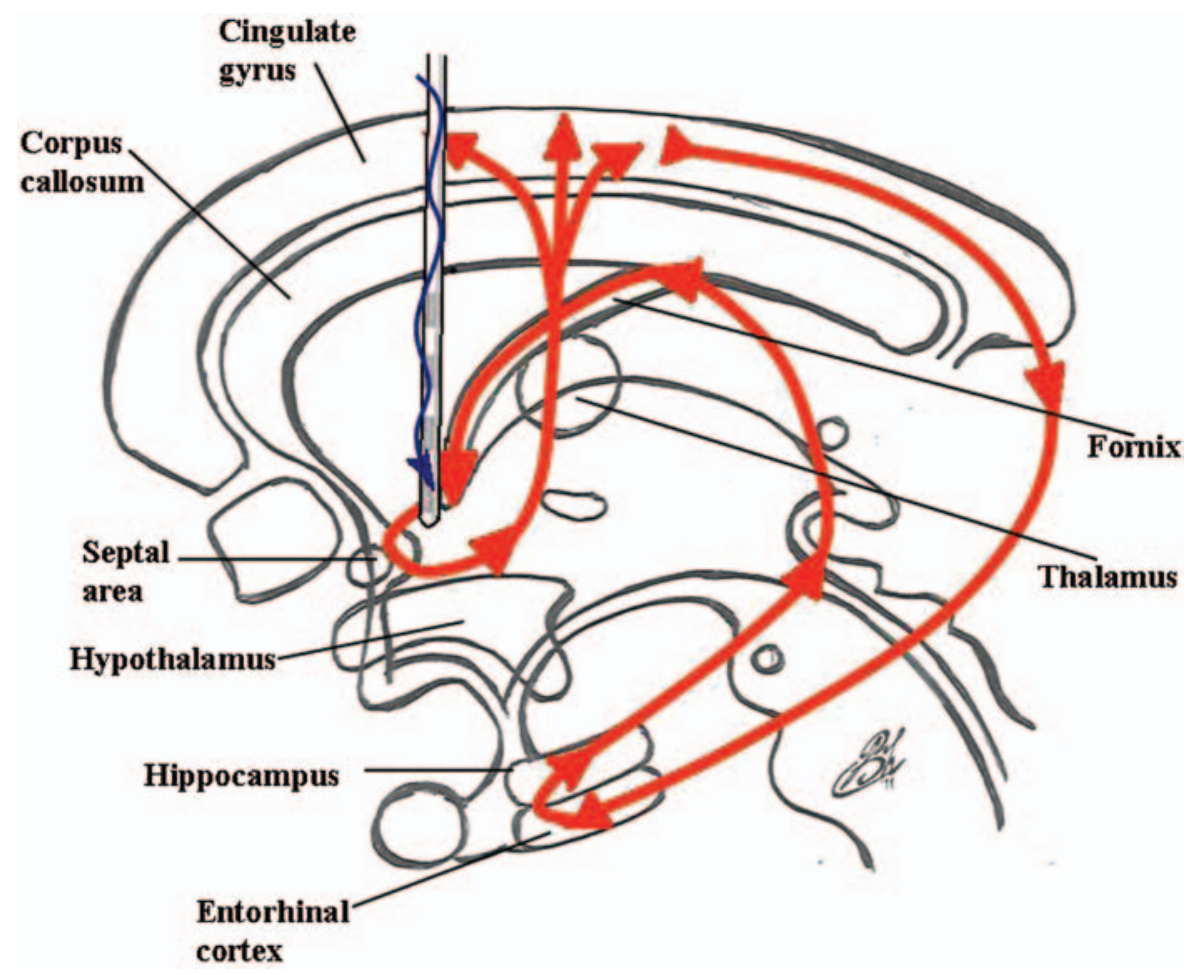

Figure 8 A schematic drawing demonstrating the mechanism of action and the activated pathways after anterior fornix DBS in Alzheimer's disease. 
Table 5 Ethical Criteria for Clinical Trials in Psychosurgery ${ }^{67}$

1. Transparent and independent discussion of patient selection from psychiatric and neurosurgical perspectives.

2. Data-driven, evidence-based rationale for target selection that surpasses a consensus-derived threshold of information for surgical intervention.

3. Demonstration of disease burden, including qualification of its severity and refractoriness to known therapy.

4. Transparent discussion of the informed consent process, including the involvement of caregivers and a qualitative demonstration of its adequacy.

5. Involvement of multiple disciplines, providing independent assessments and evaluations, and participating in patient selection and follow-up.

6. Regulated, dispassionate oversight governing the ethical conduct of clinicians and researchers, that is, divorced from the informed consent and patient-selection processes.

7. Routine, scheduled evaluations that identify obstacles and potential challenges for the ethical conduct of the trial and the dissemination of its results.

understanding of the neurophysiologic aspects of these diseases to be able to follow and keep with this progression. Indeed, psychosurgery is where all the aspects and the specialists of neuroscience regather aiming, in collaboration, to solve the mystery so-called the brain.

\section{Conflict of Interest}

None

\section{References}

1 Ackermans L, Temel Y, Cath D, et al; Dutch Flemish Tourette Surgery Study Group. Deep brain stimulation in Tourette's syndrome: two targets? Mov Disord 2006;21(5):709-713

2 American Psychiatric Association. Diagnostic and Statistical Manual of Mental Disorders: DSM-IV-TR. 4th ed. Washington, DC: American Psychiatric Association; 2000

3 Anand BK, Brobeck JR. Localization of a "feeding center" in the hypothalamus of the rat. Proc Soc Exp Biol Med 1951;77(2): 323-324

4 Andrade P, Noblesse LH, Temel Y, et al. Neurostimulatory and ablative treatment options in major depressive disorder: a systematic review. Acta Neurochir (Wien) 2010;152(4):565-577

5 Arnulf I, Ferraye M, Fraix V, et al. Sleep induced by stimulation in the human pedunculopontine nucleus area. Ann Neurol 2010; 67(4):546-549

6 Benabid AL, Pollak P, Gervason C, et al. Long-term suppression of tremor by chronic stimulation of the ventral intermediate thalamic nucleus. Lancet 1991;337(8738):403-406

7 Benton AL. Differential behavioral effects in frontal lobe disease. Neuropsychologia 1968;6:53-60

8 Berrios GE. The origins of psychosurgery: Shaw, Burckhardt and Moniz. Hist Psychiatry 1997;8(29 pt 1):61-81

9 Bewernick BH, Hurlemann R, Matusch A, et al. Nucleus accumbens deep brain stimulation decreases ratings of depression and anxiety in treatment-resistant depression. Biol Psychiatry 2010;67(2):110-116

10 Browning PG, Gaffan D, Croxson PL, Baxter MG. Severe scene learning impairment, but intact recognition memory, after cholinergic depletion of inferotemporal cortex followed by fornix transection. Cereb Cortex 2010;20(2):282-293

11 Cecchini AP, Mea E, Tullo V, et al. Vagus nerve stimulation in drugresistant daily chronic migraine with depression: preliminary data. Neurol Sci 2009;30(Suppl 1):S101-S104
12 Coccaro EF. Impulsive aggression: a behavior in search of clinical definition. Harv Rev Psychiatry 1998;5(6):336-339

13 Cox JE, Powley TL. Intragastric pair feeding fails to prevent VMH obesity or hyperinsulinemia. Am J Physiol 1981;240(5): E566-E572

14 Cummings JL. Frontal-subcortical circuits and human behavior. Arch Neurol 1993;50(8):873-880

15 Daban C, Martinez-Aran A, Cruz N, Vieta E. Safety and efficacy of vagus nerve stimulation in treatment-resistant depression. A systematic review. J Affect Disord 2008;110(1-2):1-15

16 Damasio H, Grabowski T, Frank R, Galaburda AM, Damasio AR. The return of Phineas Gage: clues about the brain from the skull of a famous patient. Science 1994;264(5162):1102-1105

17 Davidson RJ, Putnam KM, Larson CL. Dysfunction in the neural circuitry of emotion regulation-a possible prelude to violence. Science 2000;289(5479):591-594

18 Denys D, Mantione M, Figee M, et al. Deep brain stimulation of the nucleus accumbens for treatment-refractory obsessive-compulsive disorder. Arch Gen Psychiatry 2010;67(10):1061-1068

19 Falconer MA, Schurr PH. Surgical Treatment of Mental Illness. London: J\&A Churchill; 1959

20 Faris PL, Hofbauer RD, Daughters R, et al. De-stabilization of the positive vago-vagal reflex in bulimia nervosa. Physiol Behav 2008;94(1):136-153

21 Feldman RP, Alterman RL, Goodrich JT. Contemporary psychosurgery and a look to the future. J Neurosurg 2001;95(6):944-956

22 Feldman RP, Goodrich JT. Psychosurgery: a historical overview. Neurosurgery 2001;48(3):647-657, discussion 657-659

23 Filali M, Hutchison WD, Palter VN, Lozano AM, Dostrovsky JO. Stimulation-induced inhibition of neuronal firing in human subthalamic nucleus. Exp Brain Res 2004;156(3):274-281

24 Flaherty AW, Williams ZM, Amirnovin R, et al. Deep brain stimulation of the anterior internal capsule for the treatment of Tourette syndrome: technical case report. Neurosurgery 2005;57(4, Suppl):E403, discussion E403

25 Frankle WG, Lombardo I, New AS, et al. Brain serotonin transporter distribution in subjects with impulsive aggressivity: a positron emission study with [11C]McN 5652. Am J Psychiatry 2005;162(5):915-923

26 Franzini A, Marras C, Ferroli P, Bugiani O, Broggi G. Stimulation of the posterior hypothalamus for medically intractable impulsive and violent behavior. Stereotact Funct Neurosurg 2005;83(2-3):63-66

27 Freeman W. Transorbital leucotomy. Lancet 1948;2(6523): 371-373

28 Friedman DP, Goldman HW, Flanders AE, Gollomp SM, Curran WJ Jr. Stereotactic radiosurgical pallidotomy and thalamotomy with the gamma knife: MR imaging findings with clinical correlationpreliminary experience. Radiology 1999;212(1):143-150 
29 Gao G, Wang X, He S, et al. Clinical study for alleviating opiate drug psychological dependence by a method of ablating the nucleus accumbens with stereotactic surgery. Stereotact Funct Neurosurg 2003;81(1-4):96-104

30 Giacobbe P, Mayberg HS, Lozano AM. Treatment resistant depression as a failure of brain homeostatic mechanisms: implications for deep brain stimulation. Exp Neurol 2009;219(1):44-52

31 Goto M, Swanson LW. Axonal projections from the parasubthalamic nucleus. J Comp Neurol 2004;469(4):581-607

32 Gradinaru V, Mogri M, Thompson KR, Henderson JM, Deisseroth K. Optical deconstruction of parkinsonian neural circuitry. Science 2009;324(5925):354-359

33 Greenberg BD, Gabriels LA, Malone DA Jr, et al. Deep brain stimulation of the ventral internal capsule/ventral striatum for obsessive-compulsive disorder: worldwide experience. Mol Psychiatry 2010;15(1):64-79

34 Hamani C, McAndrews MP, Cohn M, et al. Memory enhancement induced by hypothalamic/fornix deep brain stimulation. Ann Neurol 2008;63(1):119-123

35 Hammond C, Bergman H, Brown P. Pathological synchronization in Parkinson's disease: networks, models and treatments. Trends Neurosci 2007;30(7):357-364

36 Hariz MI, Robertson MM. Gilles de la Tourette syndrome and deep brain stimulation. Eur J Neurosci 2010;32(7):1128-1134

37 Heath RG, Llewellyn RC, Rouchell AM. Brain mechanisms in psychiatric illness: rationale for and results of treatment with cerebellar stimulation. In: Hitchcock ER, Ballantine HT, Meyerson BA, eds. Modern Concepts in Psychiatric Surgery. Amsterdam: Elsevier/North-Holland Biomedical Press; 1979

38 Heimer L, Hoesen GW, Trimble M, Zahm DS. Anatomy of Neuropsychiatry: The New Anatomy of the Basal Forebrain and Its Implications for Neuropsychiatric Illness. Oxford: Elsevier Academic Press; 2008

39 Heinze HJ, Heldmann M, Voges J, et al. Counteracting incentive sensitization in severe alcohol dependence using deep brain stimulation of the nucleus accumbens: clinical and basic science aspects. Front Hum Neurosci 2009;3:22

40 Henderson MB, Green AI, Bradford PS, Chau DT, Roberts DW, Leiter JC. Deep brain stimulation of the nucleus accumbens reduces alcohol intake in alcohol-preferring rats. Neurosurg Focus 2010;29(2):E12

41 Holtzheimer PE III, Mayberg HS. Deep brain stimulation for treatment-resistant depression. Am J Psychiatry 2010;167(12): $1437-1444$

42 Huff W, Lenartz D, Schormann M, et al. Unilateral deep brain stimulation of the nucleus accumbens in patients with treatment-resistant obsessive-compulsive disorder: Outcomes after one year. Clin Neurol Neurosurg 2010;112(2):137-143

43 Husted DS, Shapira NA. A review of the treatment for refractory obsessive-compulsive disorder: from medicine to deep brain stimulation. CNS Spectr 2004;9(11):833-847

44 Jiménez-Ponce F, Velasco-Campos F, Castro-Farfán G, et al. Preliminary study in patients with obsessive-compulsive disorder treated with electrical stimulation in the inferior thalamic peduncle. Neurosurgery 2009;65(6, Suppl):203-209, discussion 209

45 Jiménez F, Velasco F, Salin-Pascual R, et al. A patient with a resistant major depression disorder treated with deep brain stimulation in the inferior thalamic peduncle. Neurosurgery 2005;57(3):585-593, discussion 585-593

46 Jones EG. The thalamic matrix and thalamocortical synchrony. Trends Neurosci 2001;24(10):595-601

47 Kandel ER, Schwartz JH, Jessel TM. Principles of Neural Science. 4th ed. New York: McGraw-Hill; 2000

48 Karachi C, Yelnik J, Tandé D, Tremblay L, Hirsch EC, François C. The pallidosubthalamic projection: an anatomical substrate for nonmotor functions of the subthalamic nucleus in primates. Mov Disord 2005;20(2):172-180
49 Kelley AE, Stinus L. Disappearance of hoarding behavior after 6hydroxydopamine lesions of the mesolimbic dopamine neurons and its reinstatement with L-dopa. Behav Neurosci 1985;99(3): 531-545

50 Kerr FW, Pozuelo J. Suppression of physical dependence and induction of hypersensitivity to morphine by stereotaxic hypothalamic lesions in addicted rats. A new theory of addiction. Mayo Clin Proc 1971;46(10):653-665

51 Kim MC, Lee TK, Choi CR. Review of long-term results of stereotactic psychosurgery. Neurol Med Chir (Tokyo) 2002;42(9): 365-371

52 Kling MA, Loyd D, Sansbury N, et al. Effects of short-term VNS therapy on Fos expression in rat brain nuclei. Poster presented at the 58th Annual Scientific Convention of the Society of Biological Psychiatry. San Francisco, CA; May 15-17, 2003

53 Knight G. Chronic depression and drug addiction treated by stereotactic surgery. Nurs Times 1969;65(19):583-586

54 Koob GF, Le Moal M. Neurobiology of Addiction. London: Academic Press; 2006

55 Kopell BH, Greenberg BD. Anatomy and physiology of the basal ganglia: implications for DBS in psychiatry. Neurosci Biobehav Rev 2008;32(3):408-422

56 Kopell BH, Greenberg B, Rezai AR. Deep brain stimulation for psychiatric disorders. J Clin Neurophysiol 2004;21(1):51-67

57 Kosel M, Sturm V, Frick C, et al. Mood improvement after deep brain stimulation of the internal globus pallidus for tardive dyskinesia in a patient suffering from major depression. J Psychiatr Res 2007;41(9):801-803

58 Krack P, Hariz MI, Baunez C, Guridi J, Obeso JA. Deep brain stimulation: from neurology to psychiatry? Trends Neurosci 2010;33(10):474-484

59 Kuhn J, Bauer R, Pohl S, et al. Observations on unaided smoking cessation after deep brain stimulation of the nucleus accumbens. Eur Addict Res 2009;15(4):196-201

60 Kuhn J, Gründler TO, Lenartz D, Sturm V, Klosterkötter J, Huff W. Deep brain stimulation for psychiatric disorders. Dtsch Arztebl Int 2010;107(7):105-113

61 Kuhn J, Lenartz D, Huff W, et al. Remission of alcohol dependency following deep brain stimulation of the nucleus accumbens: valuable therapeutic implications? J Neurol Neurosurg Psychiatry 2007;78(10):1152-1153

62 Kuhn J, Lenartz D, Mai JK, Huff W, Klosterkoetter J, Sturm V. Disappearance of self-aggressive behavior in a brain-injured patient after deep brain stimulation of the hypothalamus: technical case report. Neurosurgery 2008;62(5):E1182, discussion E1182

63 Laxton AW, Tang-Wai DF, McAndrews MP, et al. A phase I trial of deep brain stimulation of memory circuits in Alzheimer's disease. Ann Neurol 2010;68(4):521-534

64 LeDoux J. The emotional brain, fear, and the amygdala. Cell Mol Neurobiol 2003;23(4-5):727-738

65 Leiphart JW, Valone FH III. Stereotactic lesions for the treatment of psychiatric disorders. J Neurosurg 2010;113(6):1204-1211

66 Lippitz BE, Mindus P, Meyerson BA, Kihlström L, Lindquist C. Lesion topography and outcome after thermocapsulotomy or gamma knife capsulotomy for obsessive-compulsive disorder: relevance of the right hemisphere. Neurosurgery 1999;44(3): 452-458, discussion 458-460

67 Lipsman N, Bernstein M, Lozano AM. Criteria for the ethical conduct of psychiatric neurosurgery clinical trials. Neurosurg Focus 2010;29(2):E9

68 Lipsman N, McIntyre RS, Giacobbe P, Torres C, Kennedy SH, Lozano AM. Neurosurgical treatment of bipolar depression: defining treatment resistance and identifying surgical targets. Bipolar Disord 2010;12(7):691-701

69 Liu H, Liu Y, Yu J, et al. Vagus nerve stimulation inhibits heroinseeking behavior induced by heroin priming or heroin-associated cues in rats. Neurosci Lett 2011;494(1):70-74 
70 Lozano AM, Mayberg HS, Giacobbe P, Hamani C, Craddock RC, Kennedy SH. Subcallosal cingulate gyrus deep brain stimulation for treatment-resistant depression. Biol Psychiatry 2008;64(6): 461-467

71 Lubman DI, Yücel M, Pantelis C. Addiction, a condition of compulsive behaviour? Neuroimaging and neuropsychological evidence of inhibitory dysregulation. Addiction 2004;99(12): 1491-1502

72 Lujan JL, Chaturvedi A, McIntyre CC. Tracking the mechanisms of deep brain stimulation for neuropsychiatric disorders. Front Biosci 2008;13:5892-5904

73 Machado C, Korein J. Persistent vegetative and minimally conscious states. Rev Neurosci 2009;20(3-4):203-220

74 Maley JH, Alvernia JE, Valle EP, Richardson D. Deep brain stimulation of the orbitofrontal projections for the treatment of intermittent explosive disorder. Neurosurg Focus 2010;29(2): E11

75 Mallet L, Polosan M, Jaafari N, et al; STOC Study Group. Subthalamic nucleus stimulation in severe obsessive-compulsive disorder. N Engl J Med 2008;359(20):2121-2134

76 Malone DA Jr, Dougherty DD, Rezai AR, et al. Deep brain stimulation of the ventral capsule/ventral striatum for treatment-resistant depression. Biol Psychiatry 2009;65(4):267-275

77 Manjila S, Rengachary S, Xavier AR, Parker B, Guthikonda M. Modern psychosurgery before Egas Moniz: a tribute to Gottlieb Burckhardt. Neurosurg Focus 2008;25(1):E9

78 Mantione M, van de Brink W, Schuurman PR, Denys D. Smoking cessation and weight loss after chronic deep brain stimulation of the nucleus accumbens: therapeutic and research implications: case report. Neurosurgery 2010;66(1):E218, discussion E218

79 Marangell LB, Suppes T, Zboyan HA, et al. A 1-year pilot study of vagus nerve stimulation in treatment-resistant rapid-cycling bipolar disorder. J Clin Psychiatry 2008;69(2):183-189

80 Martínez-Fernández R, Zrinzo L, Aviles-Olmos I, et al. Deep brain stimulation for Gilles de la Tourette syndrome: a case series targeting subregions of the globus pallidus internus. Mov Disord 2011;26(10):1922-1930

81 Mayberg HS. Targeted electrode-based modulation of neural circuits for depression. J Clin Invest 2009;119(4):717-725

82 Mayberg HS, Lozano AM, Voon V, et al. Deep brain stimulation for treatment-resistant depression. Neuron 2005;45(5):651-660

83 McCracken CB, Grace AA. Nucleus accumbens deep brain stimulation produces region-specific alterations in local field potential oscillations and evoked responses in vivo. J Neurosci 2009;29 (16):5354-5363

84 McIntyre RS, Soczynska JK, Mancini D, Woldeyohannes HO, Konarski JZ, Kennedy SH. Comparing features of bipolar disorder to major depressive disorder in a tertiary mood disorders clinic. Ann Clin Psychiatry 2007;19(4):313-317

85 Medvedev SV, Anichkov AD, Polyakov YI. Physiological mechanisms of the effectiveness of bilateral stereotactic cingulotomy against strong psychological dependence in drug addicts. Hum Physiol 2003;29:492-497

86 Merrill CA, Jonsson MA, Minthon L, et al. Vagus nerve stimulation in patients with Alzheimer's disease: Additional follow-up results of a pilot study through 1 year. J Clin Psychiatry 2006;67(8): 1171-1178

87 Mindus P, Rasmussen SA, Lindquist C. Neurosurgical treatment for refractory obsessive-compulsive disorder: implications for understanding frontal lobe function. J Neuropsychiatry Clin Neurosci 1994;6(4):467-477

88 Mink JW. Neurobiology of basal ganglia and Tourette syndrome: basal ganglia circuits and thalamocortical outputs. Adv Neurol 2006;99:89-98

89 Mink JW, Walkup J, Frey KA, et al; Tourette Syndrome Association, Inc. Patient selection and assessment recommendations for deep brain stimulation in Tourette syndrome. Mov Disord 2006; 21(11):1831-1838
90 Morgan JF, Crisp AH. Use of leucotomy for intractable anorexia nervosa: a long-term follow-up study. Int J Eat Disord 2000; 27(3):249-258

91 Mpakopoulou M, Gatos H, Brotis A, Paterakis KN, Fountas KN. Stereotactic amygdalotomy in the management of severe aggressive behavioral disorders. Neurosurg Focus 2008;25(1):E6

92 Müller UJ, Sturm V, Voges J, et al. Successful treatment of chronic resistant alcoholism by deep brain stimulation of nucleus accumbens: first experience with three cases. Pharmacopsychiatry 2009;42(6):288-291

93 Nierenberg AA, Alpert JE, Gardner-Schuster EE, Seay S, Mischoulon D. Vagus nerve stimulation: 2-year outcomes for bipolar versus unipolar treatment-resistant depression. Biol Psychiatry 2008;64(6):455-460

94 Olson S. Neurobiology. Making sense of Tourette's. Science 2004;305(5689):1390-1392

95 Pallanti S, Quercioli L. Treatment-refractory obsessive-compulsive disorder: methodological issues, operational definitions and therapeutic lines. Prog Neuropsychopharmacol Biol Psychiatry 2006;30(3):400-412

96 Palop JJ, Mucke L. Synaptic depression and aberrant excitatory network activity in Alzheimer's disease: two faces of the same coin? Neuromolecular Med 2010;12(1):48-55

97 Panksepp J. Textbook of Biological Psychiatry. Hoboken, NJ: Wiley-Liss; 2004

98 Patel SR, Simpson HB. Patient preferences for obsessive-compulsive disorder treatment. J Clin Psychiatry 2010;71(11): 1434-1439

99 Paxinos G, Mai JK. The Human Nervous System. Oxford: Elsevier Academic Press; 2004

100 Porta M, Brambilla A, Cavanna AE, et al. Thalamic deep brain stimulation for treatment-refractory Tourette syndrome: twoyear outcome. Neurology 2009;73(17):1375-1380

101 Quaade F, Vaernet K, Larsson S. Stereotaxic stimulation and electrocoagulation of the lateral hypothalamus in obese humans. Acta Neurochir (Wien) 1974;30(1-2):111-117

102 Rampello L, Alvano A, Battaglia G, Bruno V, Raffaele R, Nicoletti F. Tic disorders: from pathophysiology to treatment. J Neurol 2006;253(1):1-15

103 Rasmussen SA, Eisen JL. The epidemiology and clinical features of obsessive compulsive disorder. Psychiatr Clin North Am 1992; 15(4):743-758

104 Rouaud T, Lardeux S, Panayotis N, Paleressompoulle D, Cador M, Baunez C. Reducing the desire for cocaine with subthalamic nucleus deep brain stimulation. Proc Natl Acad Sci U S A 2010; 107(3):1196-1200

105 Ruffin M, Nicolaidis S. Electrical stimulation of the ventromedial hypothalamus enhances both fat utilization and metabolic rate that precede and parallel the inhibition of feeding behavior. Brain Res 1999;846(1):23-29

106 Sackeim HA, Keilp JG, Rush AJ, et al. The effects of vagus nerve stimulation on cognitive performance in patients with treatment-resistant depression. Neuropsychiatry Neuropsychol Behav Neurol 2001;14(1):53-62

107 Sadock BJ, Sadock VA. Synopsis of Psychiatry. Philadelphia: Lippincott Williams \& Wilkins; 2005

108 Sani S, Jobe K, Smith A, Kordower JH, Bakay RA. Deep brain stimulation for treatment of obesity in rats. J Neurosurg 2007; 107(4):809-813

109 Sartorius A, Kiening KL, Kirsch P, et al. Remission of major depression under deep brain stimulation of the lateral habenula in a therapy-refractory patient. Biol Psychiatry 2010;67(2): e9-e11

110 Schiff ND, Giacino JT, Kalmar K, et al. Behavioural improvements with thalamic stimulation after severe traumatic brain injury. Nature 2007;448(7153):600-603

111 Schiff N, Purpura K. Towards a neurophysiological foundation for cognitive neuromodulation. Thalamus Relat Syst 2002;2:55-69 
112 Schlaepfer TE, Cohen MX, Frick C, et al. Deep brain stimulation to reward circuitry alleviates anhedonia in refractory major depression. Neuropsychopharmacology 2008; 33(2):368-377

113 Schlaepfer TE, Frick C, Zobel A, et al. Vagus nerve stimulation for depression: efficacy and safety in a European study. Psychol Med 2008;38(5):651-661

114 Servello D, Porta M, Sassi M, Brambilla A, Robertson MM. Deep brain stimulation in 18 patients with severe Gilles de la Tourette syndrome refractory to treatment: the surgery and stimulation. J Neurol Neurosurg Psychiatry 2008;79(2):136-142

115 Shah DB, Pesiridou A, Baltuch GH, Malone DA, O'Reardon JP. Functional neurosurgery in the treatment of severe obsessive compulsive disorder and major depression: overview of disease circuits and therapeutic targeting for the clinician. Psychiatry (Edgmont) 2008;5(9):24-33

116 Spangler WJ, Cosgrove GR, Ballantine HT Jr, et al. Magnetic resonance image-guided stereotactic cingulotomy for intractable psychiatric disease. Neurosurgery 1996;38(6):1071-1076, discussion 1076-1078

117 Stern JS, Burza S, Robertson MM. Gilles de la Tourette syndrome and its impact in the UK. Postgrad Med 2005;81:12-19

118 Tawfik VL, Chang SY, Hitti FL, et al. Deep brain stimulation results in local glutamate and adenosine release: investigation into the role of astrocytes. Neurosurgery 2010;67(2):367-375
119 Temel Y, Visser-Vandewalle V. Surgery in Tourette syndrome. Mov Disord 2004;19(1):3-14

120 Thobois S, Ardouin C, Lhommée E, et al. Non-motor dopamine withdrawal syndrome after surgery for Parkinson's disease: predictors and underlying mesolimbic denervation. Brain 2010;133(Pt 4):1111-1127

121 Tohen M, Frank E, Bowden CL, et al. The International Society for Bipolar Disorders (ISBD) Task Force report on the nomenclature of course and outcome in bipolar disorders. Bipolar Disord 2009;11(5):453-473

122 Tye SJ, Frye MA, Lee KH. Disrupting disordered neurocircuitry: treating refractory psychiatric illness with neuromodulation. Mayo Clin Proc 2009;84(6):522-532

123 Van Der Werf YD, Weerts JG, Jolles J, Witter MP, Lindeboom J, Scheltens P. Neuropsychological correlates of a right unilateral lacunar thalamic infarction. J Neurol Neurosurg Psychiatry 1999;66(1):36-42

124 Welkenhuysen M, Van Kuyck K, Das J, Sciot R, Nuttin B. Electrical stimulation in the lateral hypothalamus in rats in the activitybased anorexia model. Neurosurg Focus 2008;25(1):E7

125 Yamamoto T, Katayama Y. Deep brain stimulation therapy for the vegetative state. Neuropsychol Rehabil 2005;15(3-4):406-413

126 Zobel A, Joe A, Freymann N, et al. Changes in regional cerebral blood flow by therapeutic vagus nerve stimulation in depression: an exploratory approach. Psychiatry Res 2005;139(3):165-179 